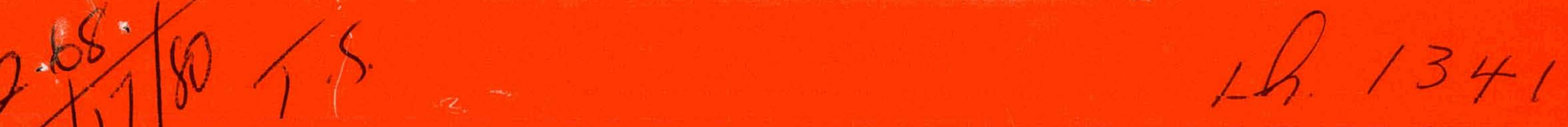

April 1980

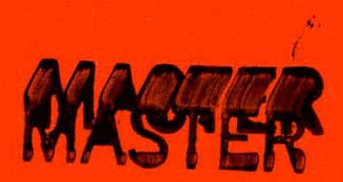

\title{
Effect of \\ Circumsolar Radiation \\ on Performance of \\ Focusing Collectors
}

P. Bendt

A. Rabl
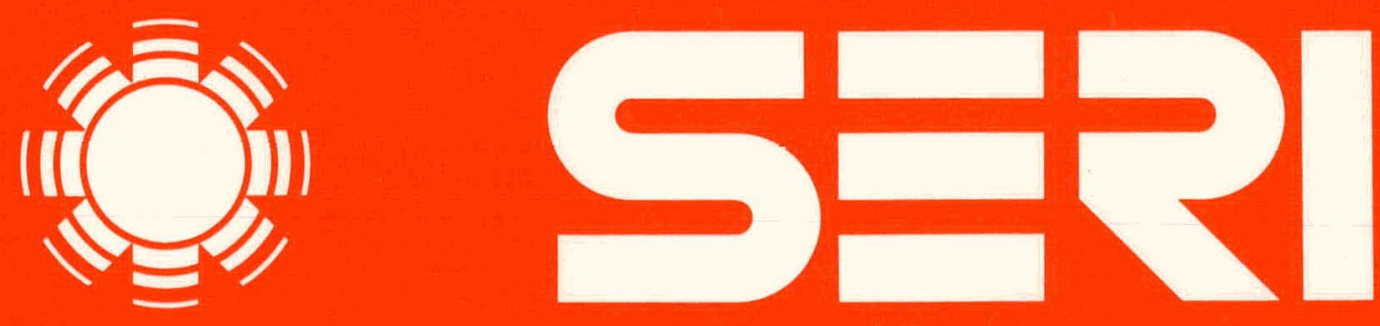

Solar Energy Research Institute

A Division of Midwest Research Institute

1617 Cole Boulevard

Golden, Colorado 80401

Operated for the

U.S. Department of Energy

under Contract No. EG-77-C-01-4042 


\section{DISCLAIMER}

This report was prepared as an account of work sponsored by an agency of the United States Government. Neither the United States Government nor any agency Thereof, nor any of their employees, makes any warranty, express or implied, or assumes any legal liability or responsibility for the accuracy, completeness, or usefulness of any information, apparatus, product, or process disclosed, or represents that its use would not infringe privately owned rights. Reference herein to any specific commercial product, process, or service by trade name, trademark, manufacturer, or otherwise does not necessarily constitute or imply its endorsement, recommendation, or favoring by the United States Government or any agency thereof. The views and opinions of authors expressed herein do not necessarily state or reflect those of the United States Government or any agency thereof. 


\section{DISCLAIMER}

Portions of this document may be illegible in electronic image products. Images are produced from the best available original document. 
Printed in the United States of America

Available from:

National Technical Information Service

U.S. Department of Commerce

5285 Port Royal Road

Springfield, VA 22161

Price:

Microfiche $\$ 3.00$

Printed Copy $\$ 5.25$

\section{NOTICE}

This report was prepared as an account of work sponsored by the United States Government. Neither the United States nor the United States Department of Energy, nor any of their employees, nor any of their contractors, subcontractors, or their employees, makes any warranty, express or implied, or assumes any legal liability or responsibility for the accuracy, completeness or usefulness of any information, apparatus, product or process disclosed, or represents that its use would not infringe privately owned rights. 
SER I /TR-34-093

UC CATEGORY: UC-62

\title{
MASTER
}

\author{
EFFECT OF CIRCUMSOLAR RADIATION \\ ON PERFORMANCE OF FOCUSING COLLECTORS
}

P. BENDT .

A. RABL

APRIL 1980

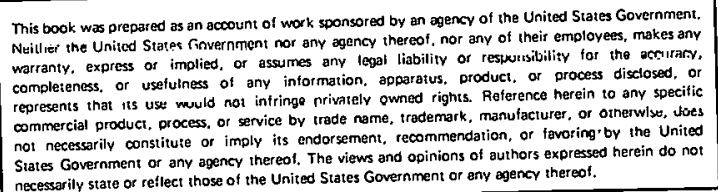

PREPARED UNDER TASK NO. 3457.33

Solar Energy Research Institute

1536 Cole Boulevard

Golderı, Cülurado 80401

A Division of Midwest Research Institute

Prepared for the

U.S. Department of Energy

Contract No. EG 77 C. $01 \cdot 4042$ 
THIS PAGE

\section{WAS INTENTIONALLY LEFT BLANK}




\section{PREFACE}

This report was prepared under Contract No. EG-77-C-01-4042, SERI Task 3457.33. The authors thank D. F. Grether and A. Hunt of Lawrence Berkeley Laboratory for providing tapes of circumsolar data and for helpful discussions.

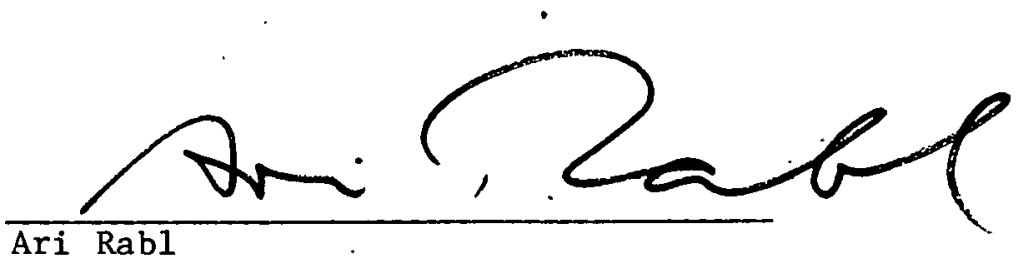

Approved for:

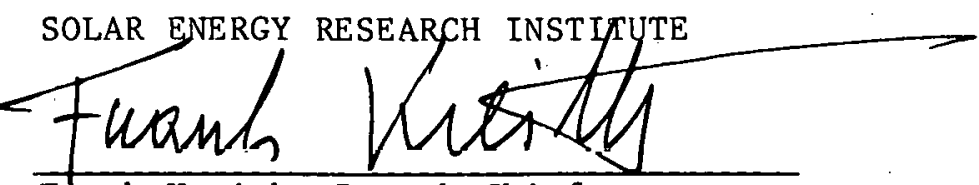

Frank Kreith, Branch Chief

Solgr Thermal-Resedrcti Branch

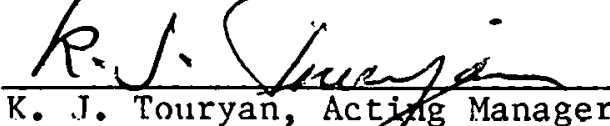

Solar Thermal, Ofan, and Wind Division 


\section{THIS PAGE \\ WAS INTENTIONALLY \\ LEFT BLANK}




\section{SUMHARY}

Circumsolar radiation is one of several factors, along with optical errors (contour, tracking, etc.), that determine the size and shape of the solar image at the receiver of a concentrating collector. The sensitivity of a collector to circumsolar radiation depends on insolation conditions and on collector parameters; it increases with geometrical concentration ratio and decreases with threshold. In this paper the Lawrence Berkeley Laboratory (LBL) circumsolar data are used to calculate the effect of circumsolar radiation on both the instantaneous and the long-term average performance of focusing collectors. To speed up the computations, the optical properties of the concentrator are expressed in terins of an angular acceptance function. The angular acceptance function and the brightness distribution of the sun are then convoluted, a procedure which requires, for each circumsolar scan, only 56 multiplications and additions (one for each of the angular intervals at which the brightness has been measured by the LBL circumsolar telescope). The instantaneous performance corresponding to particular circumsolar scans is of interest for the analysis of test results of collectors with high concentration. For most predictions of long-term average performance a far simpler approach wil1, however, be adequate. For this purpose a standard synthetic circumsolar scan has been developed that describes the brightness distribution of the solar disk ("limb darkening") and of the circumsolar region. The radiation intercepted by a receiver is calculated once for the solar portion and once for the circumsolar portion of this standard sun shape. The long-term average radiation intercepted by the receiver is then obtained by averaging the solar and the circumsolar intercept factors, weighted according to the long-term average circumsolar ratio for the location and period under study. Tested against hour-by-hour simulations, this simple approach was found to have an rms error of only $0.2 \%$, negligible compared to typical uncertainties in system performance calculations. This analysis points out the usefulness of the long-term average circumsolar ratio as a simple measure of circumsolar radiation. 
THIS PAGE

WAS INTENTIONALLY

LEFT BLANK 


\section{TABLB OF CONTENTS}

Page

Nomenclature and Defin1t1ons.............................. x111

1.0 Introduction....................................... 1

2.0 Review of LBL Results................................

2.1 Magnitude of C1rcumsolar Rat10..................... 3

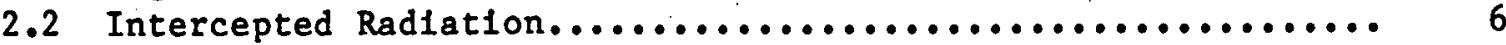

3.0 Optical Analysis.................................... 13

4.0 The Phystcs of the Linear Model......................... 17

5.0 Measurements of Solar Radiation......................... 31

6.0 Numerical Results and Validation....................... 35

7.0 Summary and Conclusions............................. 43

7.1 Instantaneous Performance.......................... 43

7.2 Long-Term Average Performance........................ 44

7.3 Average Sun Shape and Limb Darkening.................. 47

7.4 Spectral Effects................................. 47

7.5 Need for Further Data or Correlations................... 48

8.0 References........................................ 49 
THIS PAGE WAS INTENTIONALLY LEFT BLANK

,

,$\%$ 


\section{ILIST OF FIGURES}

Page

2-1 Typical Values of Pyrheliometer Reading $\mathrm{I}_{b}$ and

Circumsolar Ratio $R$ Shown with Boundary Derived by Grether........ . 4

2-2 Overestimate of Pyrheliometer (NIP) in \% at Fort Hood,

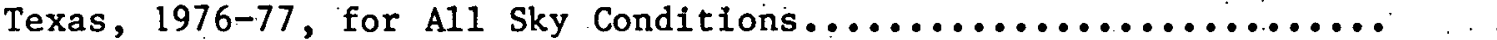

2-3 Same Selected Points from Fig. 2-2 Replotted to Show

Variation of Overestimate of Pyrheliometer with Threshold........

2-4 Sixteen Standard Circumsolar Scans of LBL................... 8

2-5 Fraction $F$ of Available Beam Insolation Lost Versus

Circumsolar Ratio $R$ for Sixteen Standard LBL Scans for Two

Central Receiver Designs.

2-6 Fraction of Average Circumsolar Radiation Lost by Two

Central Receiver Designs and by Five Collectors

With Different Effective Apertures........................

4-1 Brightness Distribution: (in Relative Units)

of Standard Clrcumsolar Scan.......................... 25

5-1 Angular Acceptance Function of Pyrheliometer (NIP) $\ldots \ldots \ldots \ldots \ldots . . . .32$ 


\section{THIS PAGE \\ WAS INTENTIONALLY \\ LEFT BLANK}




\section{ILIST OF TABLES}

Page

4-1 Standard Solar Scan for Polnt Focus Geometry................. 21

4-2 Standard Solar Scan for Line Focus Geometry.................. 23

4-3 Monthly Average Circumsolar Ratio $R_{a v}(q)$ Versus

Threshold $q$ for Each File............................ 28

6-1 Validation of Linear Model for Intercept Factor for

Parabolic Dish of Rim Angle $\phi$, Concentration $C$, and

Optical Error $\sigma \ldots \ldots \ldots \ldots \ldots \ldots \ldots \ldots \ldots \ldots \ldots \ldots \ldots \ldots \ldots \ldots \ldots \ldots \ldots$

6-2 Bias $\bar{\varepsilon}$ and rms Error $\bar{\varepsilon}$ Averaged Over Collector Designs, for Different Locations with Threshold q and Circumsolar Ratio $R_{a v}$ 6-3 The Intercept Factors $\gamma_{s}$ and $\left(\gamma_{s}\right.$ ay $-\gamma_{c}$, av for Parabolic
Trough with $90^{\circ}$ Rim Angle, Cylindrical Receiver, Geometric Concentration $C$, and Total Optical Error $\sigma \ldots \ldots \ldots \ldots \ldots \ldots \ldots \ldots \ldots$ 
THIS PAGE

\section{WAS INTENTIONALLY LEFT BLANK}




\title{
INOMENCLATURE AND DEFINITIONS
}

\author{
$B(\theta)$ angular brightness distribution of $\operatorname{sun}\left(W / \mathrm{m}^{2}\right.$ sterad) \\ C geometric concentration ratio \\ $f(\theta)$ angular acceptance function (fraction of parallel beam of radiation \\ incident on aperture that reaches receiver if optics perfect and no \\ absorption losses)
}

$f_{\sigma}(\theta)$ smeared angular acceptance function $=$ convolution of $f(\theta)$ with distribution of optical errors (fraction of parallel beam of radiation incident on aperture that reaches receiver if no absorption loss but if optics has Gaussian error distribution of width $\sigma$ )

F $\quad 1-\gamma_{S C}$

$\mathrm{I}_{\mathrm{b}}$ beam irradiance as measured by pyrheliometer at normal incidence $\left(\mathrm{W} / \mathrm{m}^{2}\right)$

circumsolar irradiance at normal incidence $=$ radiation coming from the angular range between $\delta=0.275^{\circ}$ and $\Delta=3.2^{\circ}\left(\mathrm{W} / \mathrm{m}^{2}\right)$

In radiation intercepted by receiver if no absorption losses in optics

$I_{h} \quad$ hemispherical irradiance on horizontal surface $\left(\mathrm{W} / \mathrm{m}^{2}\right)$

$I_{s} \quad$ irradiance of solar disk at normal incidence $\left(\mathrm{W} / \mathrm{m}^{2}\right)$

$\mathrm{q}_{\text {abs }} \quad$ power per collector aperture area absorbed by collector $\left(\mathrm{W} / \mathrm{m}^{2}\right)$

$\mathrm{q}_{\text {loss }}$ heat $100 \mathrm{~s}$ per aperture area $\left(\mathrm{W} / \mathrm{m}^{2}\right)$

$\mathrm{q}_{\text {out }}$ net power per aperture area delivered by collector $\left(\mathrm{W} / \mathrm{m}^{2}\right)$

R $\quad I_{c} /\left(I_{c}+I_{s}\right)=$ circumsolar ratio 


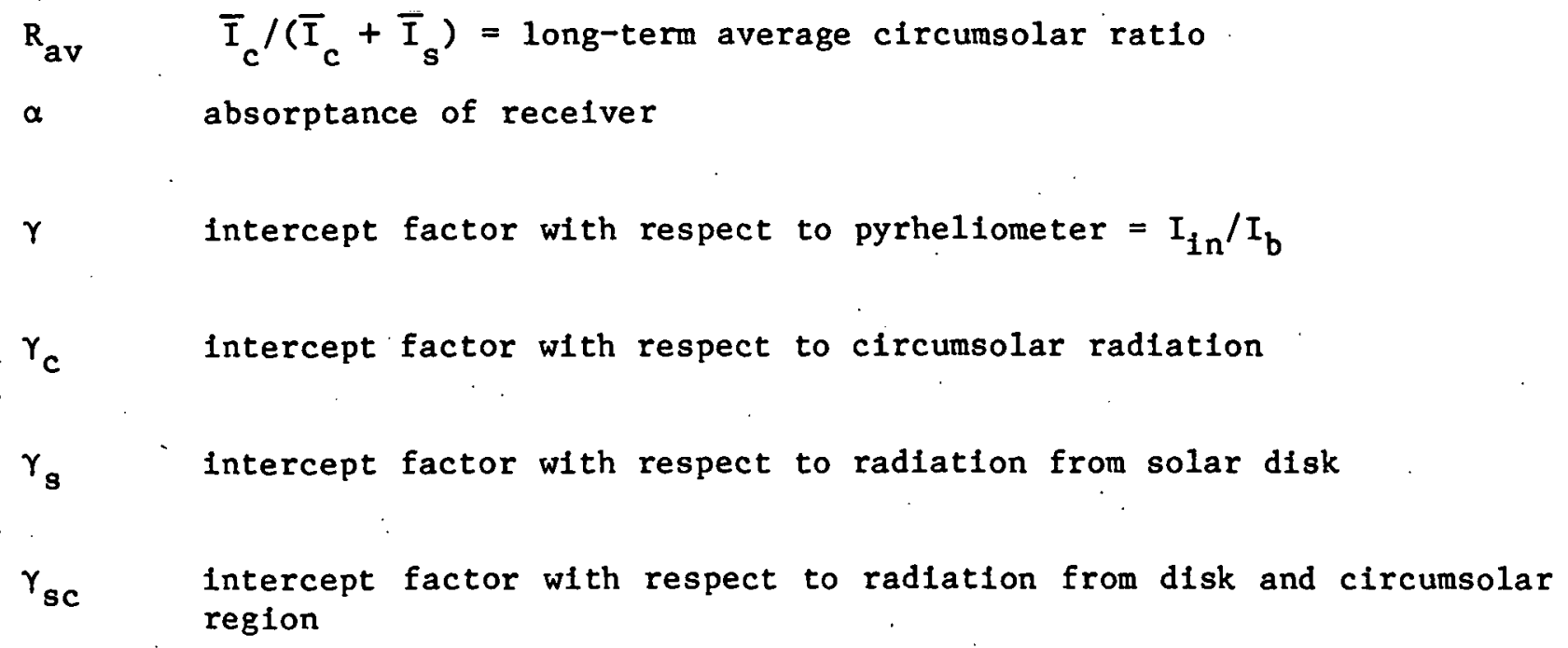
telescope) 
C1rcumsolar radiation: radiation outside solar disk but within cone of radius $\Delta=3.2^{\circ}$

Solar radiation: radiation from solar disk (the solar disk is defined to have angular radius $\delta=0.275^{\circ}$ = angular radius of sun within resolution of LBL c1rcumsolar telescope)

Beam radiation: radiation measured by pyrhellometer (also called direct radiation)

Scan (c1rcumsolar): brightness distribution of sun as measured by LBL circumsolar telescope (from $\theta=0^{\circ}$ to $\theta=3.2^{\circ}$ )

Long-term average radiation: average of instantaneous radiation values $y_{1}$

$$
\bar{y}=\frac{1}{N} \cdot \sum_{1=1}^{N}+y_{1}
$$

averaged over a large number $\mathrm{N}$ of data points. The plus sign next to the summation sign indicates that only those data are to be included that are above a spectified threshold $q$ :

Whereas the bar notation designates true averages and, In this paper, is used only for radiation values, a different kind of averaging procedure is used for circumsolar rat1os and for intercept factors. The latter quantities, denoted by a subscript "av,". are ratios of average radiation values.

NIP: normal 1ncldence pyrhellometer 


\section{SECTION 1.0}

\section{INTRODUCTION}

Due to atmospheric scattering, a significant amount of solar radiation arrives at the earth's surface from directions other than the sun. The radiation within a few degrees of the solar disk (the solar aureole) is called circumsolar radiation. Circumsolar radiation poses a problem for the analysis of concentrating collectors because, in general, the acceptance angle or field of view of a concentrator will differ markedly from that of the standard instruments available for measuring the direct or beam component $I_{b}$ of solar radiation.

By far the most common instrument that has been used and is 1ikely to be used in the future for measuring $I_{b}$ is the normal incidence pyrheliometer (NIP). Because it has a field of view characterized by an acceptance half angle 10 times larger than the solar disk itself, it includes a sizable portion of circumsolar radiation. Determination of the distribution of circumsolar radiation is particularly important for collectors with high concentration because their field of view is considerably smaller than that of the pyrheliometer; hence predictions based on pyrheliometer data may overestimate the performance significantly. (For a discussion of the connection between concentration and acceptance angle, see Winston 1970 or Rab1 1976).

Since 1974 a systematic program to measure the distribution of circumsolar radiation has been carried out by the Lawrence Berkeley Laboratory (LBL) (Grether et al. 1977a-d and 1979). Four circumsolar telescopes have been built that scan across the sun to measure the angular brightness distribution $B(\theta)$ (in $\mathrm{W} / \mathrm{m}^{2}$ steradian) with an angular resolution of 1.5 minutes of arc from the center of the sun to 0.5 degrees, and 4.5 minutes of arc from 0.5 to 3.2 degrees. They have been operated at several locations, including Albuquerque, N. Mex.; Argonne, I11.; Atlanta, Ga.; China Lake, Calif.; and Fort Hood, Tex. For the calculations in this paper, data for all of these locations with a total of about 5 years have been used.

Some analyses of circumsolar radiation are described by Grether et al. (1977a-d and 1979) and Grether and Hunt (1977); these analyses served as a starting point for our investigation. Grether et al. (1977d) evaluated the radiation intercepted by an idealized optical system with a sharply defined Fleld of view (effective aperture radius or acceptance angle) and no optical errors or aberrations. In other studies, Grether et a1. (1977c and 1979) calculated the loss of performance due to circumsolar radiation for two specific central receiver designs. Although their calculations provide a very detailed picture of the effects of circumsolar radiation on the performance of these specific optical systems at particular locations (Albuquerque, China Lake, and Fort Hood), the results are difficult to generalize to other concentrator configurations and operating conditions. The goal of our investigation is to develop a simple model of circumsolar effects that is suitable for most solar 
concentrator types and operating conditions and 18 sufficlently accurate for practical purpoges.

Before developing such a model, one must determine what is to be learned from 1t. Basically, there are two questions concerning the effect of clrcumsolar radiation on concentrating solar collectors. The first 1s: given the specific sun shape at a particular moment, what 1s the corresponding instantaneous performance of a concentrating collector? Th1s question is important for verification of the detalled agreement between test data and optical analysis. It requires as input the solar brightness as measured by a circumsolar telescope during the test. The second question concerns the average decrease in performance due to the 1088 of circumsolar radiation. This is 1mportant for system performance prediction and economic analysis. Above all, one needs to know the long-term average effect. The effect on instantaneous performance under a range of operating conditions may also be of interest. For this purpose, accuracy in an average sense is far more important than prectse agreement between model and performance for a particular moment. Relaxation of the requirement for detalled agreement in favor of average agreement is very important because it permits greater flexibility in the development of an analytical tool for modeling the effect of circumsolar radiation. Simplicity of the model is desirable to avold excessive complexity of system performance calculations and to provide intultive understanding.

In Section 2.0 of this paper the Lawrence Berkeley Laboratory reports are revlewed In order to prepare the basis for the development of the model. The optical analysis used for the calculations is outlined in Section 3.0 .

With the formulas in Section 3.0 the instantaneous performance can be calculated within the accuracy of a given clrcunsolar measurement. Thlo calculation is reasonably fast, requiring only 56 multiplications and additions per scan, provided the optical properties of the collector have been stated in terms of the angular acceptance function. The model for the long-term average effect of circumsolar radiation ts developed in Section 4.0, and a correction factor to account for the optical properties of the pyrhellometer is derived in Section 5.0. Numerleal results and validation are presented in Section 6.0, The reader who is not interested in the detalls of our analysis is advised to proceed directly to Section 7.0 , where the key results are sunmarlzed as a self-contalned users' gulde. 
SECTION 2.0

REVIEW OF LBL RESULTS

\subsection{MAGNITUDE OF CIRCUISOLAR RATIO}

For an indication of the magnitude of circumsolar radiation $I_{c}$, it is helpful to look at a plot of beam irradiance $I_{b} v s$. ratio $I_{c} / I_{b}$. The latter is approximately equal to the circumsolar ratio

$$
R=\frac{I_{c}}{I_{s}+I_{c}}
$$

as defined in Grether et al. (1977b) and in the present paper. ( $I_{b}$ is slight. Iy less than $\mathrm{I}_{s}+\mathrm{I}_{\mathrm{c}}$ because of the angular acceptance characteristics of the normal incidence pyrhellometer (NIP); see Section 5.0 below.) Many such plots are presented by Grether et al. (1977b). Figure 2-1 (from Grether 1979) for China Lake in February 1977 is quite typical. In this study the upper envelope of the data points is explained by a simple maximum scattering model based on energy conservation. The upper envelope is very closely approximated by the model (solid line) and appears to be a universal feature of circumsolar radiation. This is an important result because it shows that large values of the circumsolar ratio (in excess of $30 \%$ ) occur only when the beam irradiance is relatively low, $1 . e ., I_{b} \lesssim 500 \mathrm{~W} / \mathrm{m}^{2}$. These large circumsolar ratios can be expected to have relatively little effect on average collector performance because most useful energy is collected when $I_{b} \gtrsim 500 \mathrm{~W} / \mathrm{m}^{2}$.

Many of the data points in Fig. 2-1 cluster around small circumsolar ratios, and the average circumsolar ratio is much smaller than is implied by the upper boundary. An indication of typical average values of the circumsolar ratio is provided by Fig. 2-2 (Grether 1977d, Fig. 20). The ordinate values show how much the pyrheliometer overestimates the radiation avallable to idealized focusing collectors. The collectors are idealized because they are assumed to have a sharp cutoff $\theta_{c}$; $i . e .$, they accept all rays incldent with $\theta<\theta_{c}$ and reject all rays with $\theta>\theta_{c}$. . The solid line corresponds to $\theta_{c}=0.28^{\circ}$, the angular radius of the sun. Therefore, this line gives an estimate of the monthly average circumsolar ratio

$$
R_{a v}=\frac{\bar{I}_{c}}{\bar{I}_{s}+\bar{I}_{c}}
$$




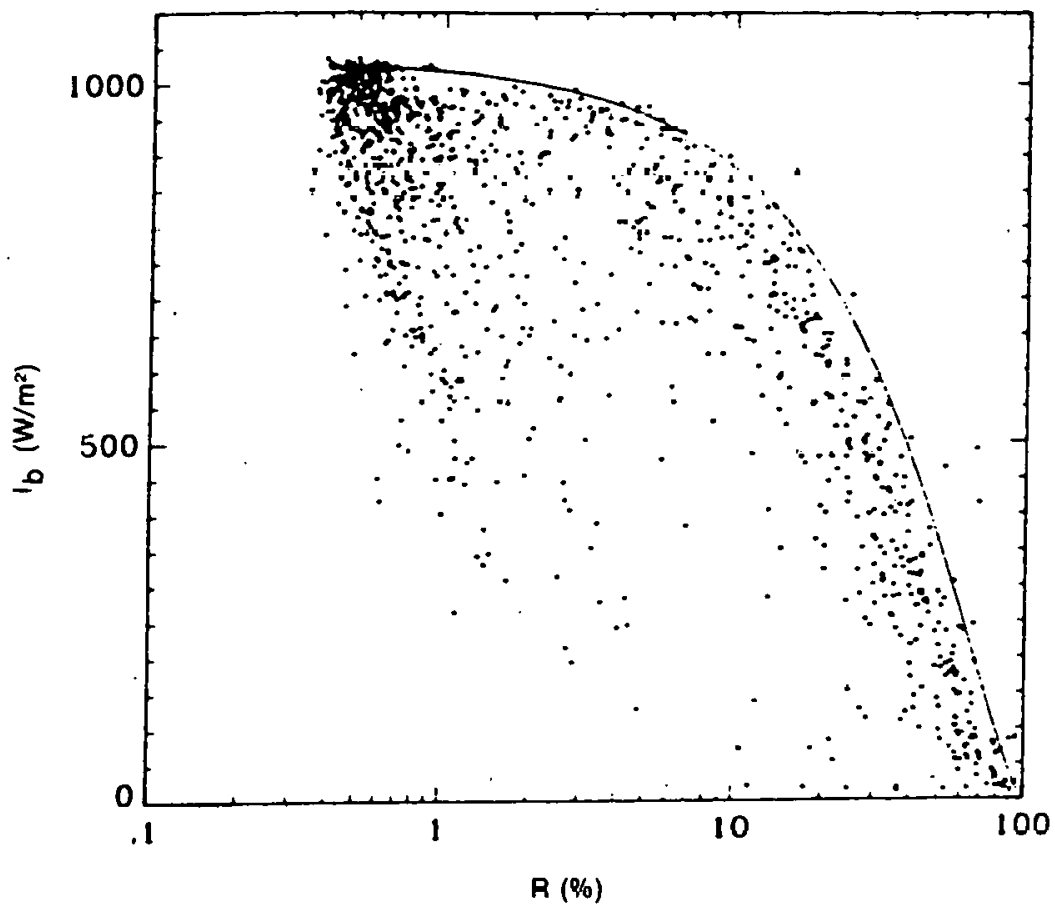

Figure 2-1. Typical Values of Pyrhellometer Reading $I_{b}$ and Circumsolar Ratio R Shown with Boundary Derived by Grether [1979].

China Lake, Calif; February 1977; all sky conditions 


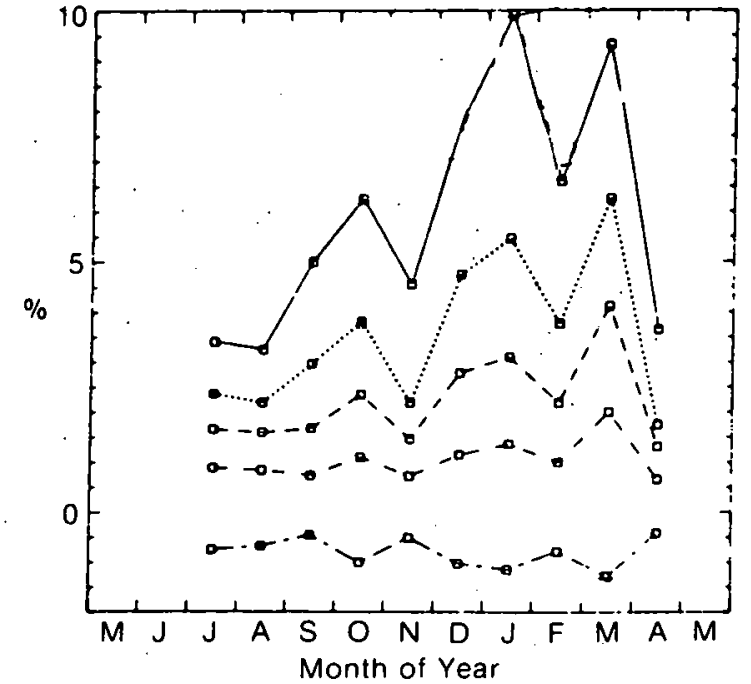

(a) Threshold $=0 \mathrm{~W} / \mathrm{m}^{2}$

EFF Aperture Radius
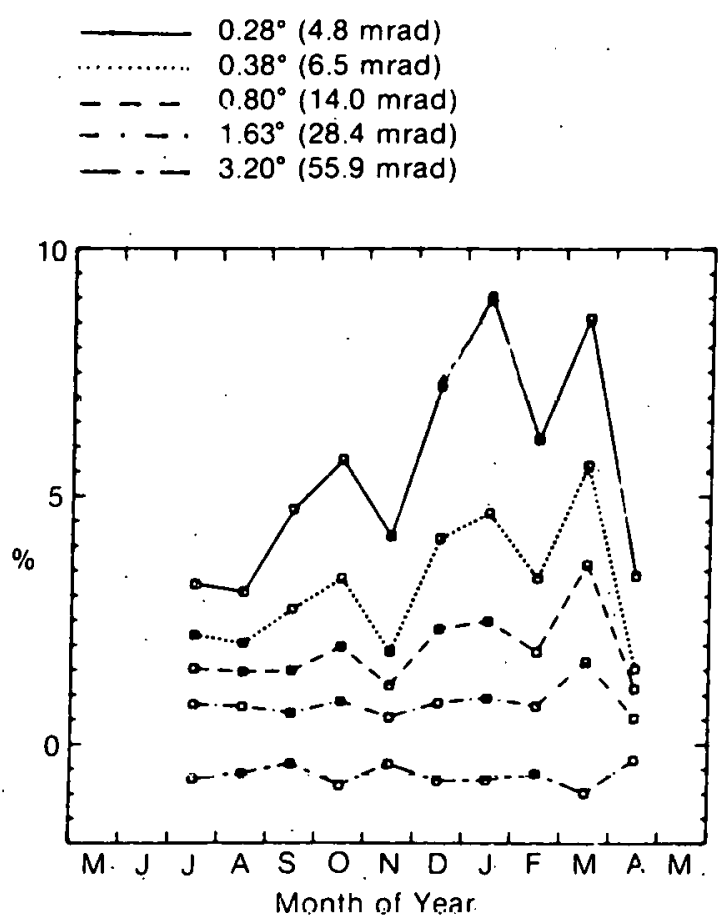

(b) Threshold $=50 \mathrm{~W} / \mathrm{m}^{2}$

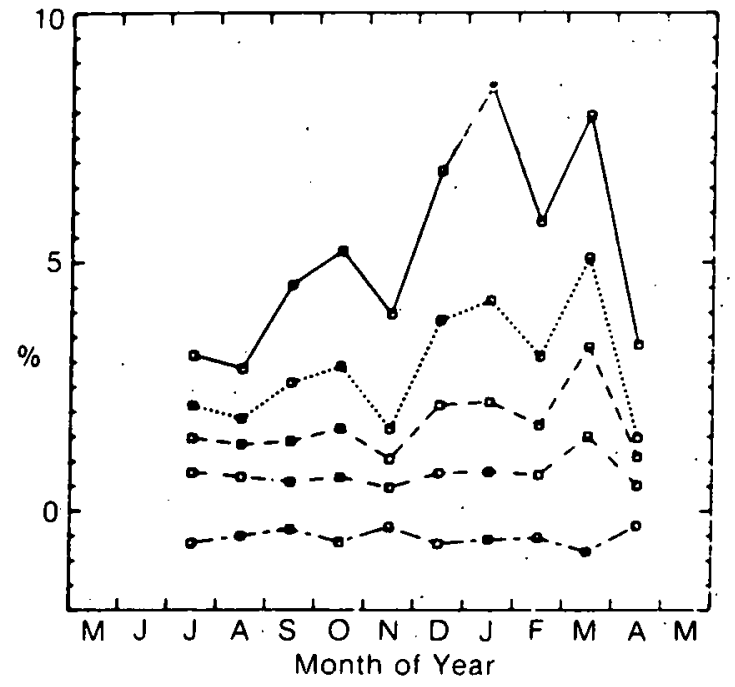

(c) Threshold $=150 \mathrm{~W} / \mathrm{m}^{2}$

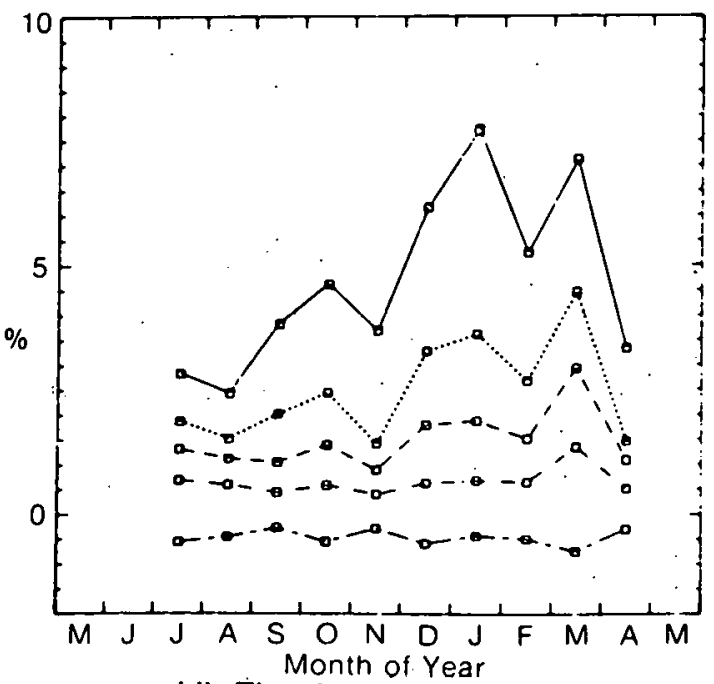

(d) Threshold $=300 \mathrm{~W} / \mathrm{m}^{2}$

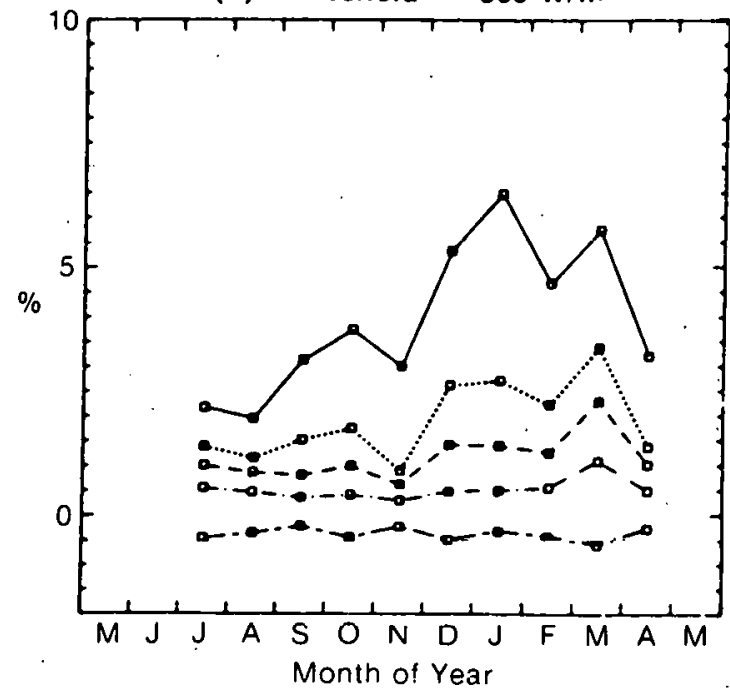

(e) Threshold $=500 \mathrm{~W} / \mathrm{m}^{2}$

Figure 2-2. Overestimate of Pyrheliometer (NIP) in \% at Fort Hood, Tex., 1976-77, for All Sky Conditions. From Grether et al. 1977d 
(The $\theta_{c}=3.20^{\circ}$ curve corresponds to negative overestimate because the pyrheliometer has a field of view smaller than $3.20^{\circ}$.)

Five graphs are presented for five values of the operating threshold: $q=0$, $50,150,300$, and $500 \mathrm{~W} / \mathrm{m}^{2}$. Figure 2-2a, for zero threshold, shows that the monthly average circumsolar ratio at Fort Hood ranges from a low of $3.5 \%$ in summer to a high of $10 \%$ in winter. Systems with nonzero threshold are turned on only when the insolation is above the threshold; therefore, periods of low insolation, which tend to be associated with higher circumsolar ratios, are excluded from the computation of $R_{a v}$. This explains why the effective circumsolar ratio in Figs. 2-2b through 2-2e decreases with threshold.

The magnitude and seasonal variation of average circumsolar ratio depends on location. of particular interest is the fact that even at a location like Fort Hood, which has relatively high circumsolar levels, the monthly average circumsolar ratio does not exceed $10 \%$. It seems that occurrences of high circumsolar radiation are sufficiently rare to keep the average circumsolar ratio well below the boundary in Fig. 2-1.

The variation of the effective circumsolar ratio $R_{a v}(q)$ with threshold $q$ is exhibited more clearly by Fig. 2-3, where some of the data of Fig. 2-2 have been replotted versus $q$. The crosses, connected by solid lines, represent the points of Fig. 2-2 for $\theta_{c}=0.28^{\circ}$ for several months. The crosses are well correlated by a straight line that passes through a circumsolar ratio of approximately $1 \%$ to $3 \%$ at a threshold of $1000 \mathrm{w} / \mathrm{m}^{2}$. This limiting value of approximately $1 \%$ to $3 \%$ depends on location and time of year and corresponds to typical circumsolar ratios on very clear days. Figure 2-3 suggests a simple linear relationship for the variation of the effective average circumsolar ratio $R_{a v}(q)$ with threshold $q$. This general pattern persists when collectors with different acceptance angles are considered. For example, the circles connected by dotted lines in Fig. 2-3 show that the $\theta_{c}=0.8^{\circ}$ points of Fig. 2-2 also decrease linearly with threshold q.

\subsection{INTERCEPTED RADIATION}

Another feature of Fig. 2-2 is that the "overestimate of NIP" for all systems with an acceptance half angle $\theta_{c}$ between $0.28^{\circ}$ and $2.8^{\circ}$ tends to be proportional to $R_{a v}$. This general hehavinr is found also in the analysis of realistic collectors; e.g., the central receiver (Grether et al. 1977c). To simplify the circumsolar analysis of the central recelver, Grether and Hunt (1977) selected 16 standard circumsolar scans such that the shape of any real scans could be approximated by one of these 16. Normalized to unity at $\theta=0$, the brightness distribution $B(\theta)$ for these standard scans is plotted in Fig. 2-4 versus angle $\theta$ from the center of the sun.

Figure 2-5 shows for the 16 standard scans the fraction $F$ of the irradiance $I_{s}+I_{c}$ that is lost by the central receiver designs proposed by Martin Marietta and McDonnell Douglas. $F$ is defined such that 


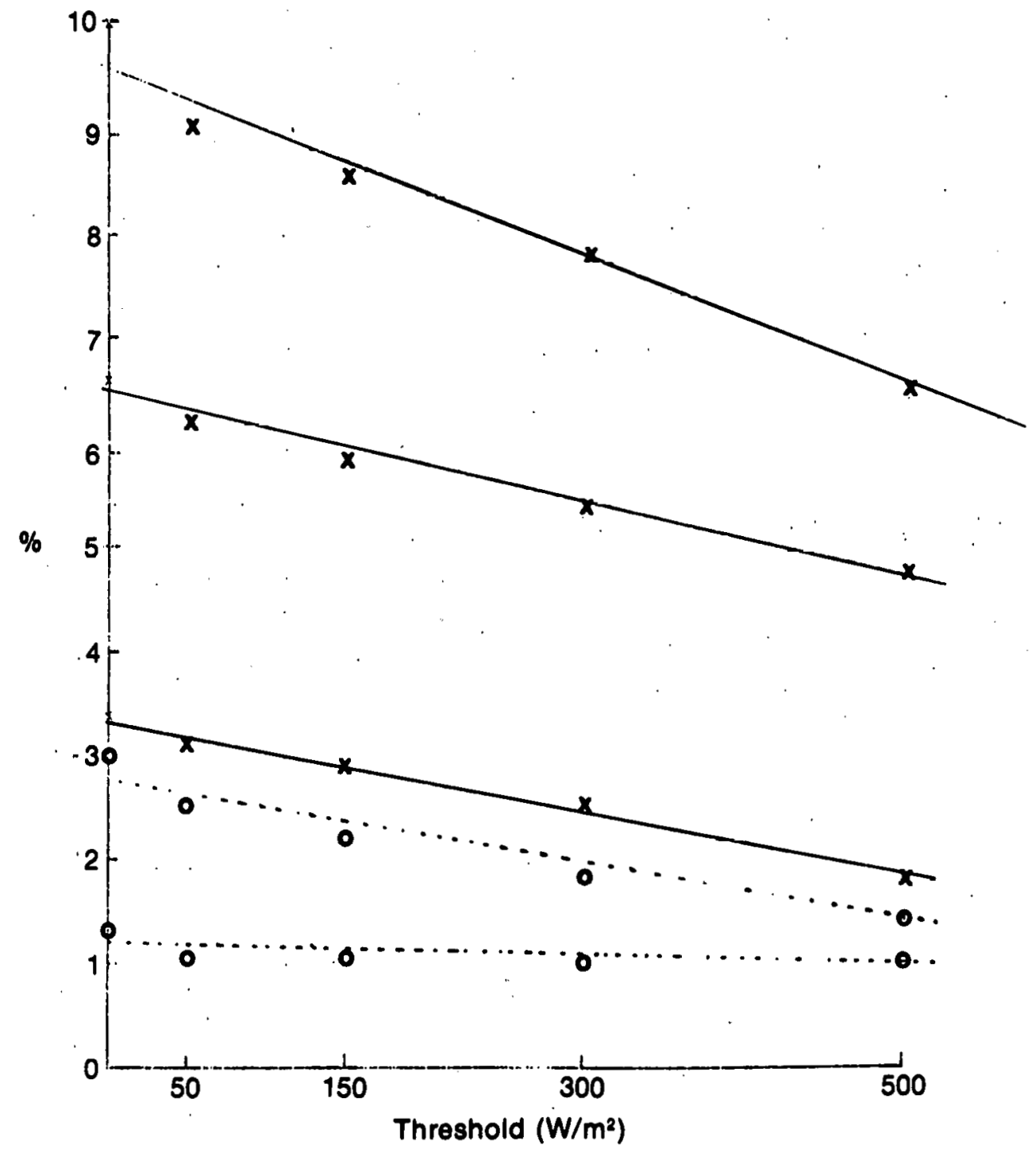

Figure 2-3. Some Selected Points from Figure 2-2. Replotted to Show Varlatlon of Overestimate of Pyinellometer with Threshold. Fieids of view of $0.28^{\circ}$ (solid lines) and $0.80^{\circ}$ (dashed lines) 


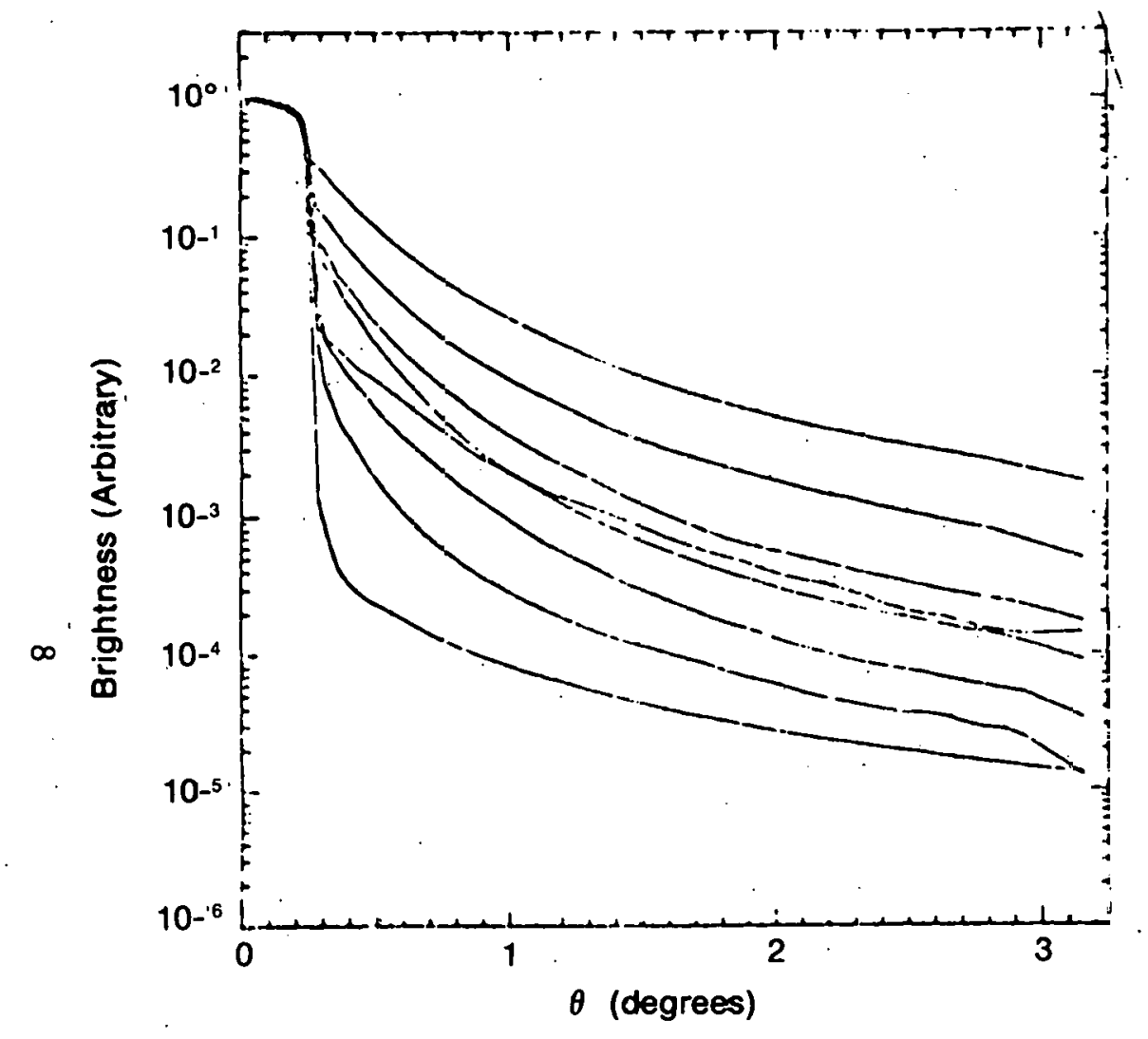

(a) Telescope 2 (Albuquerque)

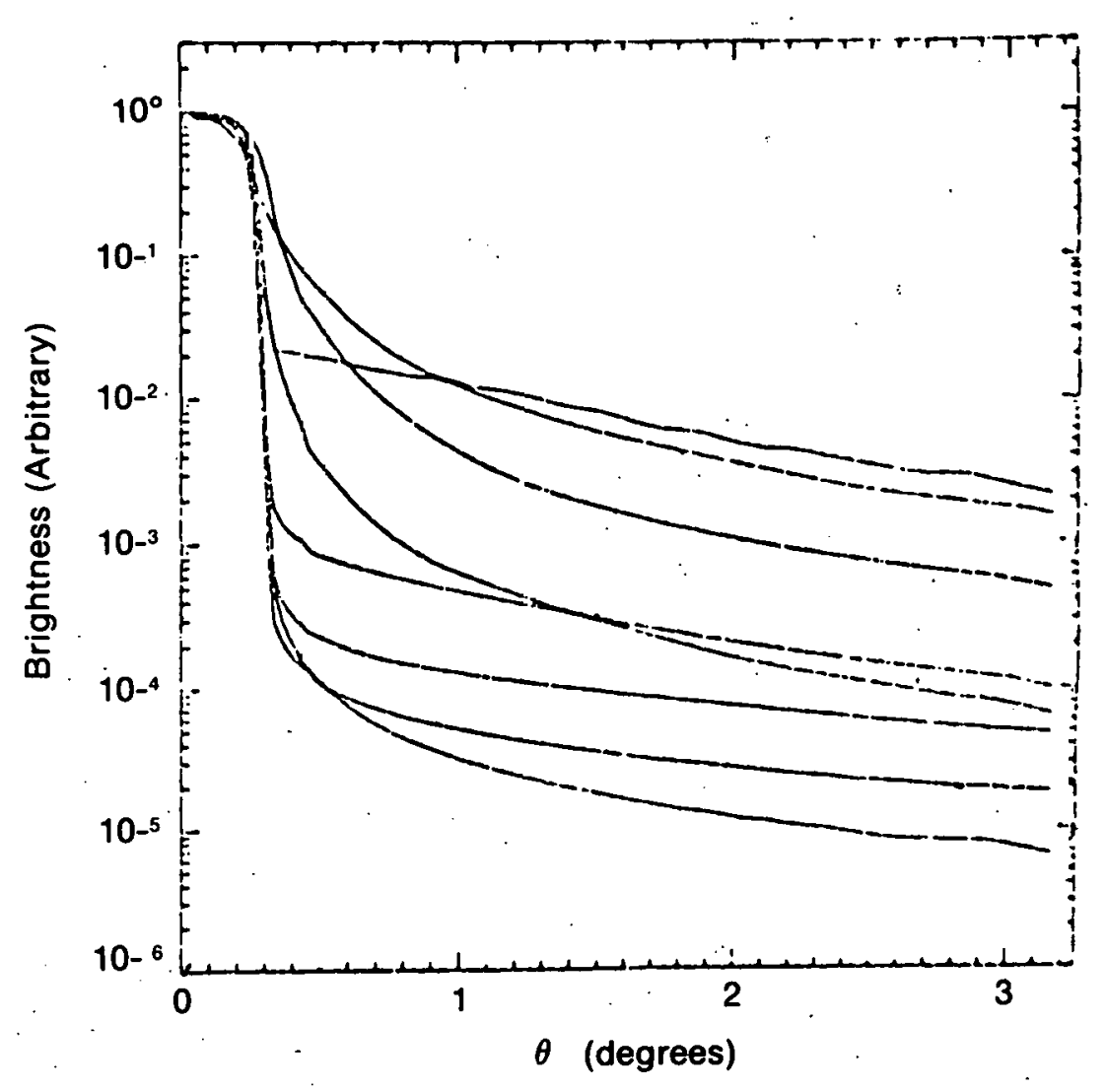

(b) Telescope 3 (Ft. Hood)

Figure 2-4. Sixteen Standard Circumsolar Scans of LBL

From Grether and Hunt 1977. Standard profiles (nomalized) 


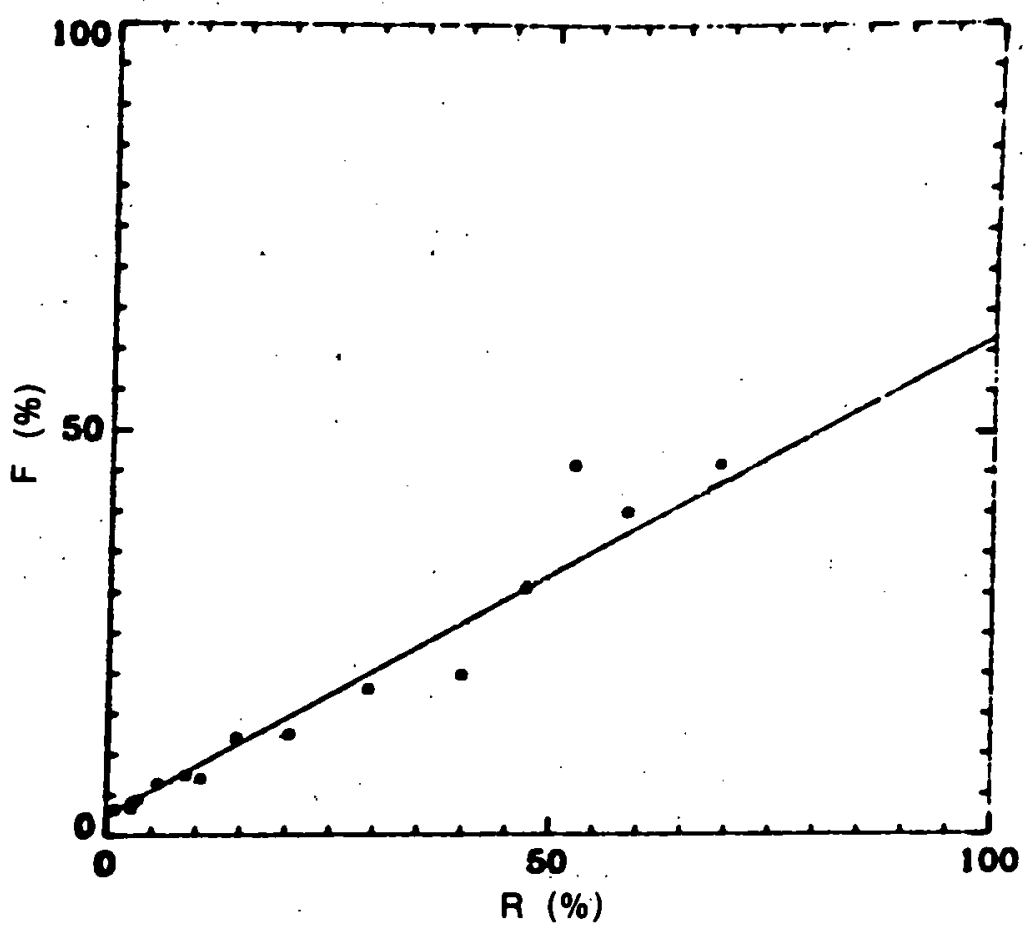

(a) Martin Marietta Pllot Design

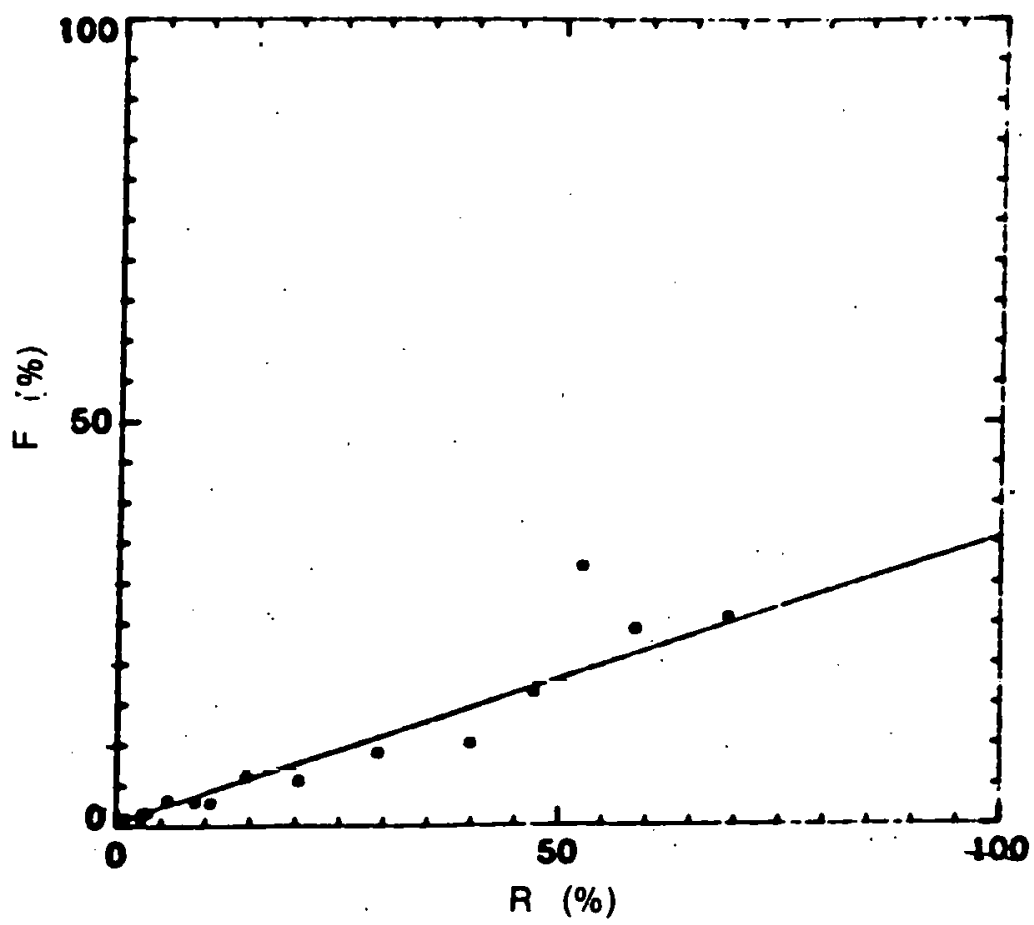

(b) McDonnell Douglas Pllot Design

Figure 2-5. Fraction $F$ of Avallable Beam Insolation Lost Versus Circumsolar Ratio R for 16 Standard LBL Scans for Two Central Receiver Designs 


$$
I_{\text {in }} \cdot(1-F)\left(I_{s}+I_{c}\right)
$$

Is the amount of radiation intercepted by the recelver when the solar plus circumsolar radiation is $I_{s}+I_{c} \cdot F$ includes all optical errors and aberratIons but no absorption 108ses; hence, $F$ depends only on concentrator geometry and sun shape. Flgure 2-5 suggests an approximately linear correlation between $F$ and the c1rcumsolar rat10:

$$
F=F_{0}+F^{\prime} \frac{\dot{I}_{c}}{\left(I_{s}+I_{c}\right)},
$$

where $F_{0}$ and $F^{\prime}$ depend on the optics of the collector but are 1ndependent of Insolation. Combining Eqs. 2-2 and 2-3 ylelds

$$
I_{1 n}=\left(1-F_{0}\right)\left(I_{s}+I_{c}\right)-F^{\prime} \cdot I_{c} ;
$$

thus a constant fraction $F^{\prime}$ of circumsolar radiation is 1ost. This phenomenon is verffied by the results of the detalled slmulations that are shown in F1g. 2-6 (Grether et al. 1977.c, F1g. 7) as the fraction of circumsolar radiation $I_{c}$ that is lost. For the two central recelver designs and for 1dealized optics with varlous acceptance half angles, the fraction of $I_{c}$ that is lost depends only weakly (at most $\pm 10 \%$ relative variation) on season and location.

The near constancy of the curves in F1g. 2-6 suggests that Eq. 2-3 may actual$1 y$ be a very good correlation when averaged over a large number of solar scans, even though the points for the 16 standard LBL scans in F1g. 2-5 deviate conslderably from the straight 11ne. The large deviations are not surprising because the 16 standard scans were not selected to be representative of any possible correlations between sun shape, circumsolar ratio, and beam insolation. The deviation from the straight line $1 \bar{s}$ particularly strong fur high c1rcumsolar rat108, but this is of little concern since high circumsolar ratios are not associsted with signiflcant amounts of collectible energy.

For the remainder of this paper it is more convenfent to work with the intercept factor

$$
r_{s c}=\frac{I_{\text {In }}}{I_{s}+I_{c}}
$$

$\left(\gamma_{s c}=1-F\right.$ in the notation of Grether et al. 1977c). Equation 2-4 1s a model for the instantaneous performance corresponding to a particular circumsolar scan; however, as a linear equation $\ln _{s}+I_{c}$ and $I_{1 n}$, It also holds 


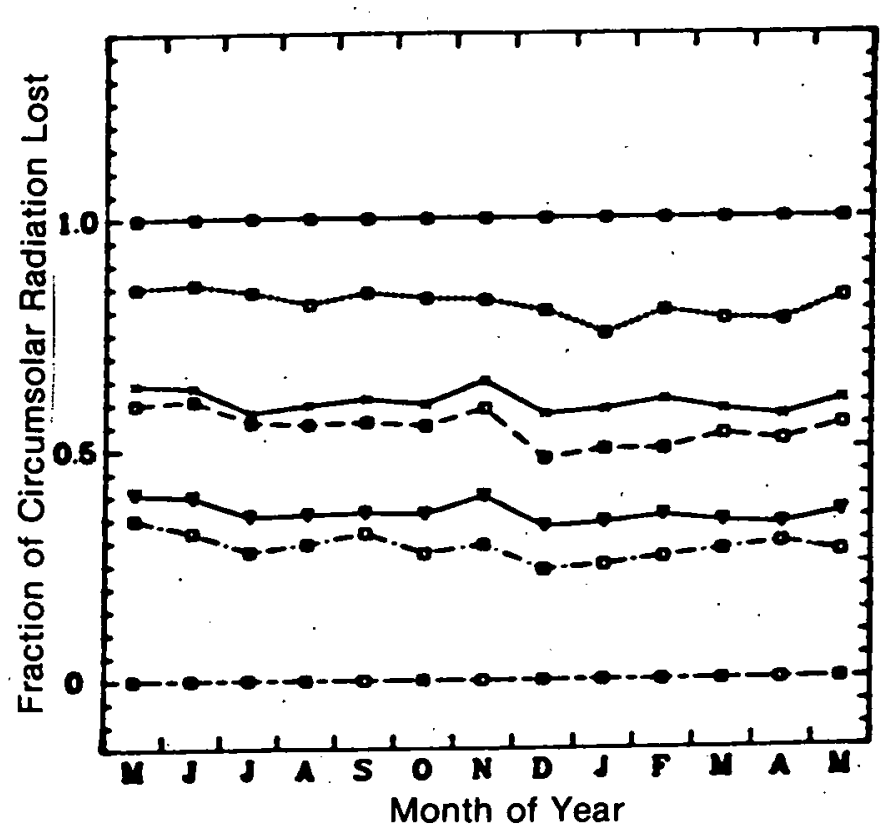

(a) Albuquerque, N. Mex.

1976-77

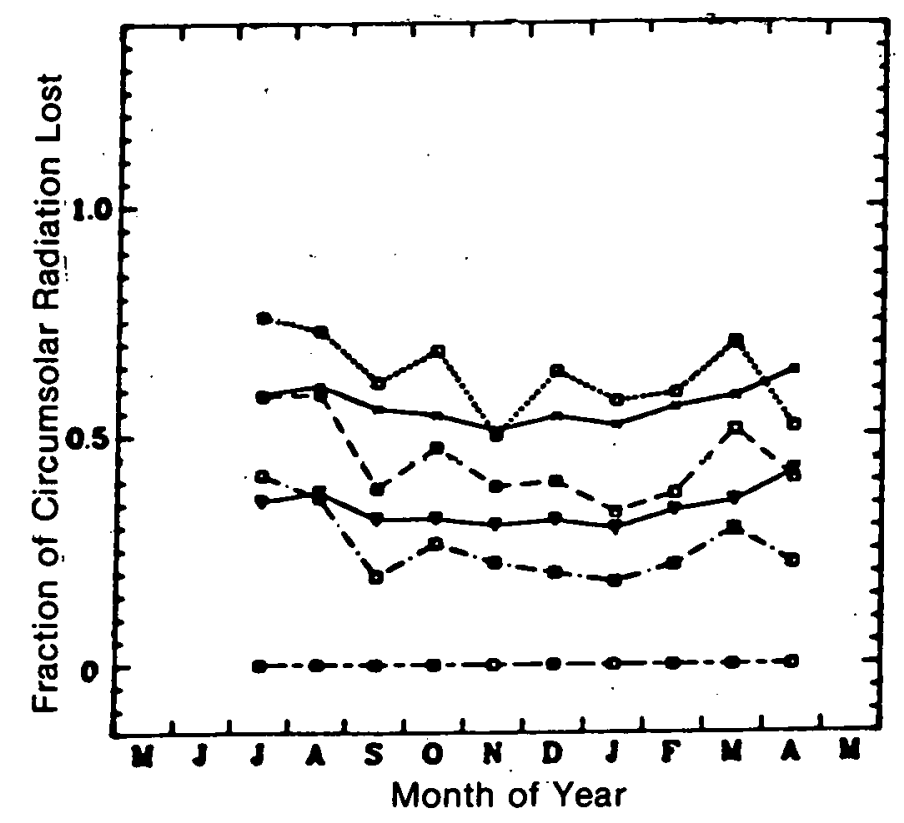

(c) Ft. Hood, Tex. 1876-77

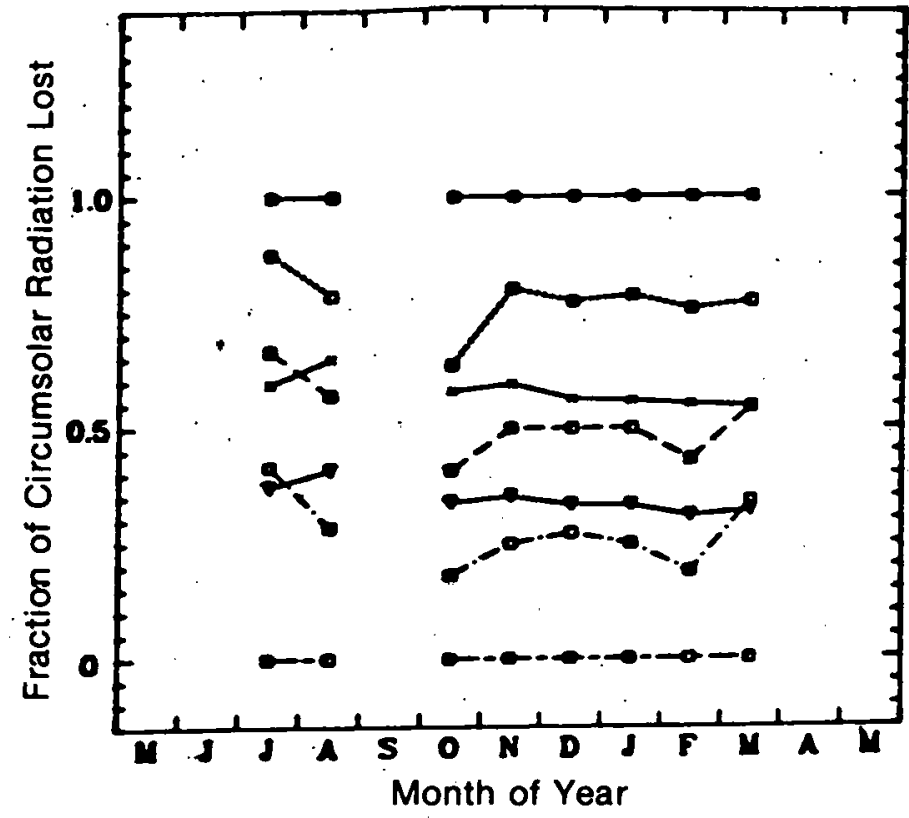

(b) China Lake, Calli. 1976-77
EFF Aperture Radius

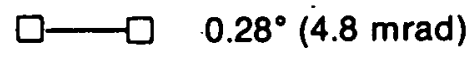

$\square \cdots . . . . \square \quad 0.38^{\circ}(6.5 \mathrm{mrad})$

$\square-\square \quad 0.80^{\circ}(14.0 \mathrm{mrad})$

$\square-.-\square \quad 1.63^{\circ}(28.4 \mathrm{mrad})$

$\square--\square \quad 3.20^{\circ}(55.9 \mathrm{mrad})$

$\times \quad$ Martin Marietta Pilot

$\triangle \quad$ McDonnell Douglas Pilot

Figure 2-6. Fraction of Average Circumsolar Radiation Lost by Two Central Receiver Designs and by Five Collectors with Different Effective Apertures. Threshold $=50 \mathrm{~W} / \mathrm{m}^{2}$. 


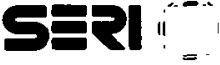

true when the insolation values are time averaged irrespective of the frequency distributions. Figure 2-6 and Eq. 2-4 suggest the following simple model for calculating the average effect of circumsolar radiation. The long-term average intercept factor

$$
\gamma_{s c, a v}=\frac{\bar{I}_{\text {in }}}{\bar{I}_{s}+\bar{I}_{c}}
$$

Is given by an expression of the form

$$
\gamma_{s c, a v}=\left(1-F_{0}\right)-F^{\prime} R_{a v}(q) \text {, }
$$

where $R_{a v}(q)$ is the effective average circumsolar ratio corresponding to a threshold $q$ and given in Fig. 2-3. The coefficients $\left(1-F_{0}\right)$ and $F^{\prime}$ depend on the optics of the collector but not on insolation. $\left(1-F_{0}\right)$ is the intercept factor for a perfectly clear sky $\left(I_{c}=0\right)$. The questions that remain. to be investigated in this paper are: how accurate is this model, and how does one calculate $\left(1-F_{0}\right)$ and $F^{\prime}$ ? 


\section{SBCTION 3.0}

\section{OPTICAL ANALYSIS}

The crucial quantity to be calculated in this paper is the intercept factor $\gamma_{s c}$ of Eq. 2-5. Once $\gamma_{s c}$ is known, the radiation $q_{a b s}$ absorbed by the receiver is obtained by multiplying the intercepted radiation $I_{\text {in }}=\gamma_{s c}$ $\left(I_{s}+I_{c}\right)$ by the effective reflectance-transmittance-absorptance product ( $\left.\rho \tau \alpha\right)$ of the collector:

$$
q_{a b s}=(\rho \tau \alpha) \gamma_{s c}\left(I_{s}+I_{c}\right)
$$

For thermal collectors, the efficiency is found by subtracting heat loss $\mathrm{q}_{10 s s}$ (in $\mathrm{W} / \mathrm{m}^{2}$ per aperture area) and normalizing by $I_{s}+I_{c}$ :

$$
\begin{aligned}
\eta & =\left(q_{a b s}-q_{10 s s}\right) /\left(I_{s}+I_{c}\right) \\
& =(p \tau \alpha) \gamma_{s c}-q_{1 o s s} /\left(I_{s}+I_{c}\right)
\end{aligned}
$$

For the calculation* of $\gamma_{s c}$ it is convenient to define the angular acceptance function $f(\theta)$ as that fraction of a uniform beam of parallel rays incident on the aperture at an angle $\theta$ from the optical axis that reaches the receiver if the optics are perfect. This function accounts for aberrations of a perfect parabola at the nonzero incidence angle $\theta$ but does not include optical er rors. For a parabolic dish with a flat receiver, the calculation of $f(\theta)$ is quite tedious (Bendt and Rabl 1979), but the results can be approximated with sufficient accuracy by a second-order polynomial in $\mathrm{C}^{2}$ :

$$
f(\theta)=\left\{\begin{array}{ll}
1 & \text { for } \sqrt{c} \theta<v_{1} \\
a+b c \theta^{2}+c\left(c \theta^{2}\right)^{2} & \text { for } v_{1}<\sqrt{c} \theta<v_{2} \\
0 & \text { for } \sqrt{c} \theta>v_{2}
\end{array} .\right.
$$

$C$ is the geometric concentration ratio, and the coefficients $a, b, c, v_{1}$, and $v_{2}$ depend only on the rim angle $\phi$; they are tabulated in Bendt and Rab1 (1979).

Seen through the optics of the collector, the sun appears smeared because of optical errors. These arise from deviations of the reflector contour from the

*In the interest of brevity, some detalls are omitted that are explained in Bendt and Rab1 1979 and Bendt et a1. 1979. 
design shape, lack of perfect specularity of the reflector surface, displacement of the receiver relative to the reflector, and incorrect tracking. Even though the individual error distributions may not be exactly Gaussian, their combination can be approximated, in most cases, by a Gaussian distribution of width $\sigma$, the rms angular standard deviation of a reflected ray from its design direction.

The intercept factor is the convolution of the angular acceptance function $f(\theta)$, the optical error distribution, and the angular brightness distribution $B(\theta)$ of the sun. To carry out the calculations in this paper it is most convenient to define a function $f_{\sigma}(\theta)$ as the convolution of $f(\theta)$ with the error distribution:

$f_{\sigma}(\theta)=\frac{1}{2 \pi \sigma^{2}} \iint_{-\infty}^{\infty} f\left[\left(\theta_{x}^{2}+\theta_{y}^{2}\right) 1 / 2\right] \exp \left(-\frac{\left(\theta-\theta_{x}\right)^{2}+\theta_{y}^{2}}{2 \sigma^{2}}\right) d \theta_{x} d \theta_{y}$.

The function $f_{\sigma}(\theta)$, the "smeared angular acceptance function," is the fraction of a parallel and uniform beam of radiation incident on the aperture of a real collector with optical errors that reaches the receiver. The intercept factor is simply the product of $f_{\sigma}(\theta)$ and the normalized brightness distribution $B(\theta) /\left(I_{s}+I_{c}\right)$, integrated over all angles $\theta$ :

$$
\gamma_{s c}=\frac{2 \pi}{\left(I_{s}+I_{c}\right)} \int_{0}^{\Delta} \theta f_{\sigma}(\theta) B(\theta) d \theta
$$

The intercept factor $\gamma_{s c}$ can be computed quickly fơr a large number of circumsolar scans if $f_{\sigma}(\theta)$ is calculated once for each set of concentrator parameters and for each of the angles at which $B(\theta)$ is measured and if $i t$ is then stored in the computer memory.

The angular acceptance function for the line focus case is given in Bendt et a1. (1979). The expression analogous to Eq. 3-4 is

$$
f_{\sigma, 1 i n e}(\theta)=\frac{1}{\sqrt{2 \pi} \sigma} \int_{-\infty}^{\infty} f\left(\theta-\theta^{\prime}\right) \exp \left(-\frac{\theta^{\prime}}{2 \sigma^{2}}\right) d \theta^{\prime}
$$

The intercept factor can be computed by transforming the circumsolar scan to linear geometry 
$\gamma_{s c, I I n e}=\frac{4}{\left(I_{s}+I_{c}\right)} \int_{0}^{\Delta} f_{\sigma, I i n e}\left(\theta_{x}\right) d \theta_{x} \int_{0}^{\Delta} B\left[\left(\theta_{x}^{2}+\theta_{y}^{2}\right)^{1 / 2}\right] d \theta_{y}$

If the calculation is to be repeated for many scans, however, it is faster to transform the smeared angular acceptance function $f_{\sigma, 11 n e}(\theta)$ to point focus geometry by averaging it over azimuthal directions. The result

$$
f_{\sigma, \text { equiv }}(\theta)=\frac{1}{2 \pi} \int_{0}^{2 \pi} f_{\sigma, 11 n e}(\theta \cos \phi) d \phi
$$

Is the equivalent smeared point focus acceptance function of a line focus collector and, therefore, can be used directly in Eq. 3-5.

If an accurate system simulation is needed and if circumsolar data of the LBL type are avallable, we recommend that Eq. 3-5 be used to calculate the instantaneous collector efficiency corresponding to each scan. Since the LBL data are given as brightness values at 56 angular intervals, such a calculation requires only 56 multiplications and additions for each scan, assuming, of course, that $\theta \mathrm{f}_{\sigma}(\theta)$ has been previously calculated and stored in memory.* The angular acceptance function and hence $f_{\sigma}(\theta)$ can be readily calculated for any concentrator using elther ray tracing or the analytical technique described in Bendt and Rabl (1979), which is much faster and more accurate.

*For the central recelver $f_{\sigma}$ may vary slightly with the zentth and azimuth of the sun, in which case several functions have to be stored. 


\section{Sझ尺I*}




\section{SECTIOA 4.0}

\section{THE PHYSICS OF THE LINRAR MODEL}

To understand the linear form of Eq. 2-4 and to motivate our own analysis, it is instructive to take another look at the 16 standard scans in Fig. 2-4. These scans can be characterized as a nearly uniform solar disk with a sharp edge around $4.7 \mathrm{mrad}$, followed by a circumsolar tail which has a similar shape for all scans. The brightness in the circumsolar region varies from scan to scan, but the relative change of brightness with angle is not very different; in other words, the curves run fairly parallel in the circumsolar region. Mathematically, such behavior can be described by a brightness function of the form

$$
B(\theta)=\left\{\begin{array}{lll}
\beta_{s}(\theta) & \text { for } & \theta<\delta \approx 4.7 \mathrm{mrad} \\
a_{c}(\theta) & \text { for } & \theta>\delta \approx 4.7 \mathrm{mrad},
\end{array}\right.
$$

where the constant a is related to the clrcumsolar ratio $R$.

The corresponding solar disk irradiance is

$$
I_{s}=2 \pi \int_{0}^{\delta} \theta \beta_{s}(\theta) d \theta,
$$

and the circumsolar irradiance is

$$
I_{c}=2 \pi a \int_{\delta}^{\Delta} \theta B_{c}(\theta) d \theta \text {. }
$$

In terms of the circumsolar ratio $R=I_{c} /\left(I_{s}+I_{c}\right)$, the constant a is given by

$$
a=\frac{R \int_{0}^{\delta} \theta \beta_{s}(\theta) d \theta}{(1-R) \int_{\delta}^{\Delta} \theta \beta_{c}(\theta) d \theta} .
$$


Now Eq. 3-5 is used to calculate the intercept factor

$$
\gamma_{8 c}=\frac{I_{1 n}}{I_{s}+I_{c}}
$$

corresponding to this brightness distribution:

$$
\gamma_{s c}=\frac{2 \pi}{\left(I_{s}+I_{c}\right)}\left(\int_{0}^{\delta} \theta \beta_{s}(\theta) f_{\sigma}(\theta) d \theta+a \int_{\delta}^{\Delta} \theta \beta_{c}(\theta) f_{\sigma}(\theta) d \theta\right) \text { (4-5) }
$$

It is convenient to define a quantity

$$
\gamma_{s}=\frac{2 \pi}{I_{s}} \int_{0}^{\delta} \cdot \dot{\theta}_{s}(\theta) f_{\sigma}(\theta) d \theta
$$

as the intercept factor for radiation from the solar disk, and an analogous quantity, which is independent of $a$,

$$
\gamma_{c}=\frac{2 \pi a}{I_{c}} \int_{\delta}^{\Delta} \theta \beta_{c}(\theta) f_{\sigma}(\theta) d \theta
$$

as the Intercept factur for circumsolar radiation. In terms of $\gamma_{s}$ and $\gamma_{C}$, Eq. 4-5 can be written as

$$
\gamma_{s c}=\frac{\gamma_{s} I_{8}+\gamma_{c} I_{c}}{I_{s}+I_{c}}
$$

which has a simple physical interpretation. The intercept factor $\gamma_{s c}$ is the welghted average of the intercept factor $\gamma_{g}$ for the solar disk and the intercept factor $\gamma_{c}$ for the circumsolar region. By Inserting the circumsolar racio $R$, one can rearrange Eq. 4-8 in a slightly more convenlent form:

$$
\gamma_{B C}=\gamma_{B}-\left(\gamma_{B}-r_{c}\right) R \text {, }
$$

which is precisely the linear model (Eq. 2-4) suggested by the analysis of Grether et al. For the instantaneous performance associated with a particular circumsolar scan, this equation is a rather crude model, as shown by the scatter of data points about the trend line In F1g. 2-5 and as expected from the fact that individual circumsolar scans can deviate significantly from the average shape suggested by F1g. 2-4. Th1s is of 11ttle concern, however, since the instantaneous performance for a particular scan can be calculated readily from Eqs. 3-5 or 3-7. 
The linear model does turn out to be remarkably accurate for predicting the long-term average performance; therefore, we proceed to derive the equivalent of Eq. 4-9 for the calculation of the long-term average. The long-term average Irradiance $\bar{I}$ is defined as the average over a large number $N$ of data

$$
\bar{I}=\frac{1}{N} \sum_{i=1}^{N} I(1)
$$

with appropriate subscripts indicating solar, circumsolar, and intercepted components. The subscript plus sign under the summation sign means that only those periods with intercepted irradiance above a specifled threshold $q$ are to be included. The average could be defined for any time period (e.g., a year, a month, a time of day) and, 1deally, it should be calculated from many years' worth of data. Because a model for predicting the long-term average intercepted irradiance $\overline{\mathrm{I}}_{\text {in }}$ is desired, given the long-term average solar and circumsolar irradiance $\bar{I}_{s}+\bar{I}_{c}$, an average intercept factor is defined as

$$
\gamma_{s c, a v} \equiv \frac{\bar{I}_{i n}}{\bar{I}_{s}+\bar{I}_{c}} \text {. }
$$

In contrast to the bar notation for genuine averages, the subscript "av" designates ratios of averages in this paper. Retracing the steps from Eq. 4-5 to Eq. 4-9 yields an expression for $\gamma_{s c, a v}$ of the same form as Eq. 4-9:

$$
\gamma_{s c, a v}=\gamma_{s, a v}-\left(\gamma_{s, a v}-\gamma_{c, a v}\right) R_{a v},
$$

where $R_{a v}$ is the long-term average circumsolar ratio

$$
R_{a v} \equiv \frac{\bar{I}_{c}}{\bar{I}_{s}+\bar{I}_{c}}
$$

and $\gamma_{s, a v}$ and $\gamma_{c, a v}$ are defined as

$$
\gamma_{s, a v} \equiv \frac{2 \pi}{\bar{I}_{s}} \int_{0}^{\delta} \theta \bar{B}(\theta) f_{\sigma}(\theta) d \theta
$$


and

$$
\gamma_{c, a v} \equiv \frac{2 \pi}{\bar{I}_{c}} \int_{\delta}^{\Delta} \theta \bar{B}(\theta) f_{\sigma}(\theta) d \theta .
$$

The long-term average irradiance from the solar disk,

$$
\overline{\mathrm{I}}_{\mathbf{s}}=2 \pi \int_{0}^{\delta} \theta \overline{\mathrm{B}}(\theta) \mathrm{d} \theta \text {, }
$$

Is the integral over the disk of the long-term average brightness distribution

$$
\bar{B}(\theta)=\frac{1}{N} \sum_{i=1}^{N}+B_{i}(\theta),
$$

and analogously the average circumsolar irradiance is

$$
\bar{I}_{c}=2 \pi \int_{\delta}^{\Delta} d \theta \theta \bar{B}(\theta) \text {. }
$$

Equation 4-12 is a tautology when used with only a single set of data. The equation is useful because an excellent approximation can be obtalned fur ally set of circumsolar data at any location or time or threshold if $\gamma_{s}$ av and $\gamma_{c, a v}$ are calculated for a single synthetic circumsolar scan. For this synthetic scan, we take the average over all the circumsolar scans supplied by Lawrence Berkeley Laboratory. This average scan $\bar{B}(\theta)$ is tabulated in Table 4-1 for point focus geometry and in Table 4-2 for line focus geometry; it is plotted in Fig. 4-1.*

The fact that the brightness of the disk decreases somewhat with $\theta$ is called "limb darkening." Analytical expressions for the 1imb-darkening effect have been published in many places; e.g., Biggs and Vittitoe (1979). However, they were based on only a few measurements and theretore are not necessarily reliable as descriptions of the average brightness distribution. The simulations reported in Section 6.0 show that the average distribution $\bar{B}(\theta)$ in

*A peculiarity of the circumsolar data corresponding to high circumsolar ratios is a very slight increase in brightness at the edge of the scan. Assuming that this unphysical behavior is due to inaccuracies at the edge of the operating range of the circumsolar telescope, we have corrected the last two entries ( $53.887 \mathrm{mrad}$ and $55.196 \mathrm{mrad})$ by extrapolation from smaller angles. 
Table 4-1. STANDARD SOLAR SGAN FOR POINT FOCUS GEOMETRY

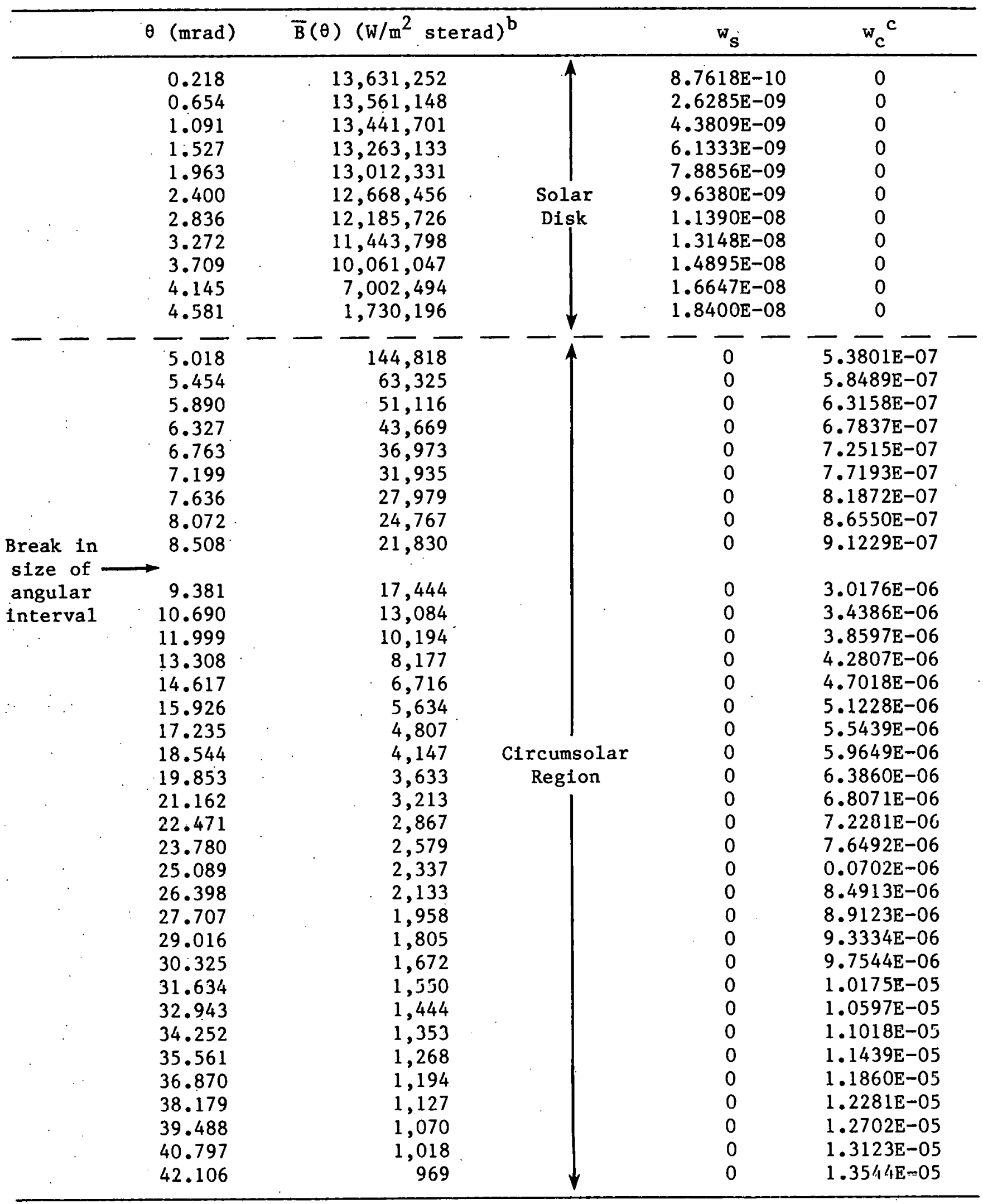


Table 4-1. STANDARD SOLAR SCAN FOR POINT FOCUS GEOAETRY ${ }^{a}$

(concluded)

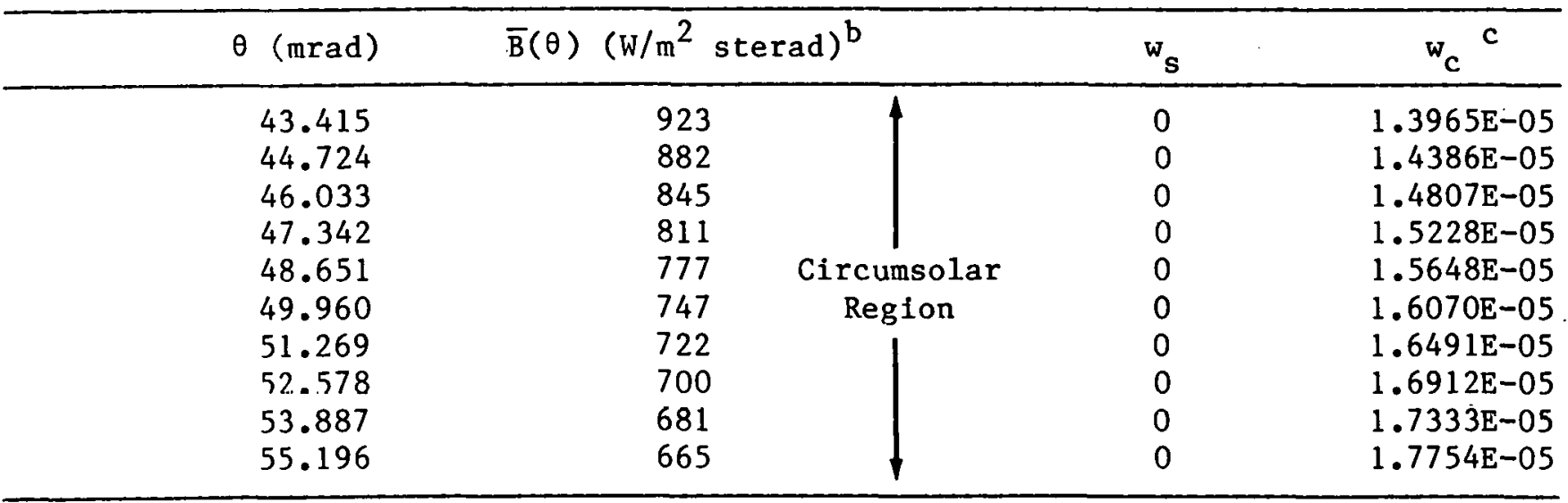

${ }^{a}$ Solar radius $0.275^{\circ}$ (disk plus resolution of instrument).

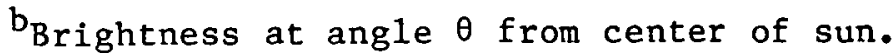

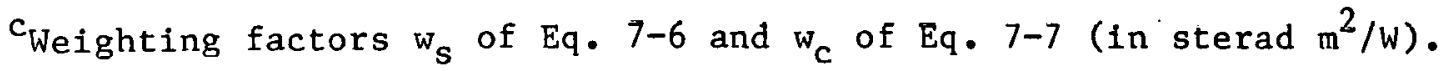


Table 4-2. STANDARD SOLAR SCAN FOR LIIB FOCUS GBOMGTRY

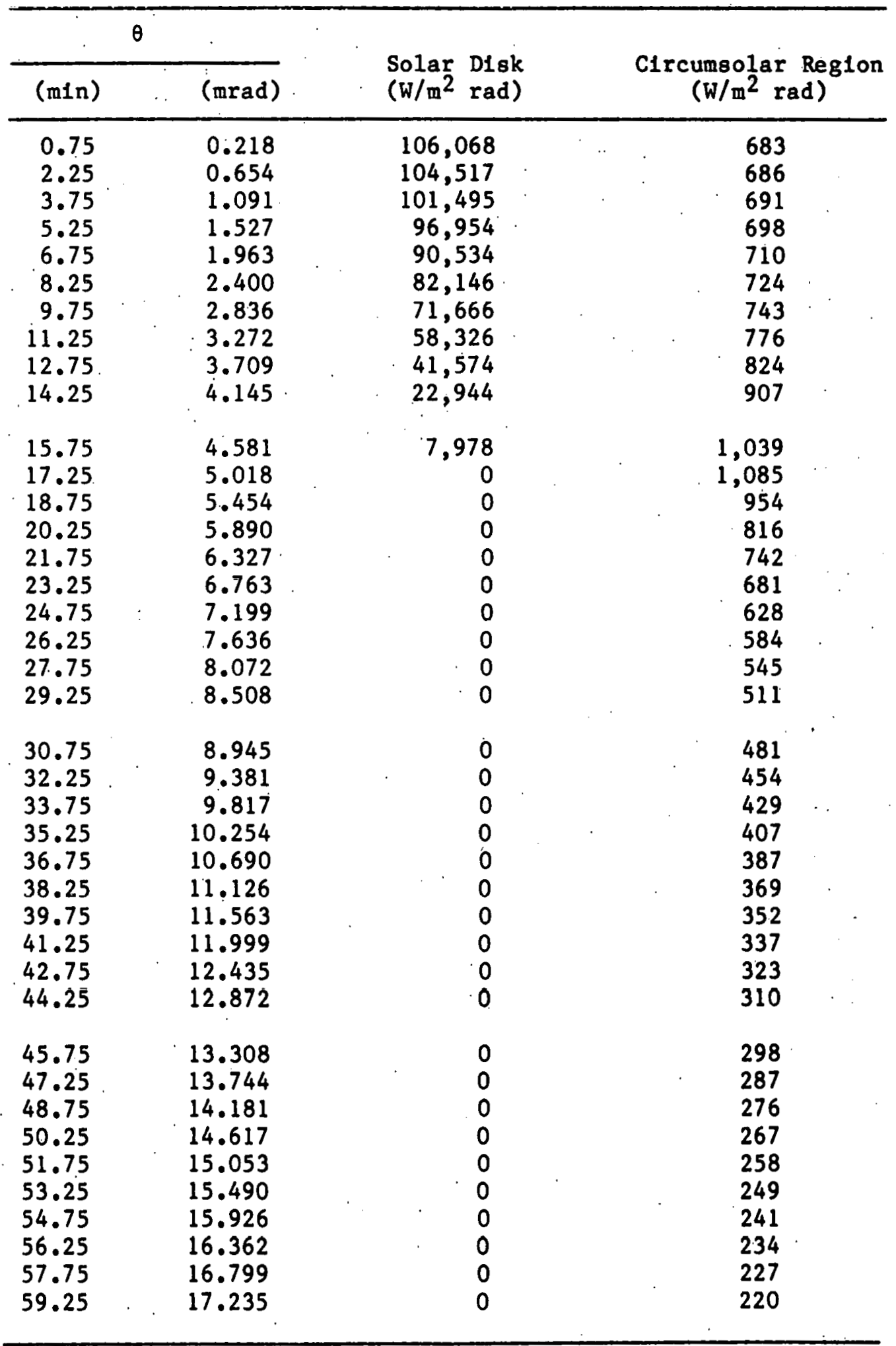


Table 4-2. STANDARD SOLAR SCAN FOR LIRE FOCOS GEOMETRY (continued)

\begin{tabular}{|c|c|c|c|c|}
\hline \multicolumn{2}{|c|}{$\theta$} & \multirow{2}{*}{$\begin{array}{l}\text { Solar } \\
\left(\mathrm{W} / \mathrm{m}^{2}\right.\end{array}$} & \multirow{2}{*}{$\begin{array}{l}\text { Disk } \\
\text { rad) }\end{array}$} & \multirow{2}{*}{$\begin{array}{c}\text { Circumsolar Region } \\
\left(\mathrm{W} / \mathrm{m}^{2} \mathrm{rad}\right)\end{array}$} \\
\hline$(m 1 n)$ & (mrad) & & & \\
\hline 60.75 & 17.671 & $\cdot$ & 0 & 214 \\
\hline 62.25 & 18.108 & & 0 & 207 \\
\hline 63.75 & 18.544 & & 0 & 202 \\
\hline 65.25 & 18.980 & & 0 & 196 \\
\hline 66.75 & 19.417 & & 0 & 191 \\
\hline 68.25 & 19.853 & & 0 & 186 \\
\hline 69.75 & 20.289 & & 0 & 181 \\
\hline 71.25 & $2 n .726$ & & $n$ & 176 \\
\hline $72 . \overline{75}$ & 21.162 & & 0 & 172 \\
\hline 74.25 & 21.598 & & 0 & 168 \\
\hline 75.75 & 22.035 & & 0 & 164 \\
\hline 77.25 & 22.471 & & 0 & 160 \\
\hline 78.75 & 22.907 & & 0 & 156 \\
\hline 80.25 & 23.344 & & 0 & 153 \\
\hline 81.75 & 23.780 & & 0 & 149 \\
\hline 83.25 & 24.216 & & 0 & 146 \\
\hline $84.75^{\circ}$ & 24.653 & & 0 & 143 \\
\hline 86.25 & 25.089 & & 0 & 139 \\
\hline 87.75 & 25.525 & & 0 & 136 \\
\hline 89.25 & 25.962 & & 0 & 133 \\
\hline 90.75 & 26.398 & & 0 & 131 \\
\hline 92.25 & 26.834 & ( & 0 & 128 \\
\hline 93.75 & 27.271 & & 0 & 125 \\
\hline 95.25 & 27.707 & & 0 & 123 \\
\hline 96.75 & 28.143 & & 0 & 120 \\
\hline 98.25 & 28.580 & & 0 & 118 \\
\hline 99.75 & 29.016 & & 0 & 115 \\
\hline 101.25 & 29.452 & & 0 & 113 \\
\hline 102.75 & 29.889 & & 0 & 111 \\
\hline 104.25 & 20.325 & & 0 & 108 \\
\hline 105.75 & 30.761 & & 0 & 106 \\
\hline 107.35 & 31,198 & & $n$ & 104 \\
\hline 108.75 & 31.634 & & 0 & 102 \\
\hline 110.25 & 32.070 & & 0 & 100 \\
\hline 111.75 & 32.507 & & 0 & 98 \\
\hline 113.25 & 32.943 & & 0 & 96 \\
\hline 114.75 & 33.379 & & 0 & 94 \\
\hline 116.25 & 33.816 & & 0 & 92 \\
\hline 117.75 & 34.252 & & 0 & 91 \\
\hline 119.25 & 34.688 & & 0 & 89 \\
\hline
\end{tabular}


Table 4-2. STANDARD SOLAR SCAN FOR LINE FOCUS GEOMETRY (continued)

\begin{tabular}{|c|c|c|c|c|}
\hline \multicolumn{2}{|c|}{$\theta$} & \multirow{2}{*}{$\begin{array}{l}\text { Solar } \\
\text { (W/m }\end{array}$} & \multirow{2}{*}{$\begin{array}{l}\text { Disk } \\
\text { rad) }\end{array}$} & \multirow{2}{*}{$\begin{array}{l}\text { Circumsolar Region } \\
\left(\mathrm{W} / \mathrm{m}^{2} \mathrm{rad}\right)\end{array}$} \\
\hline$(m i n)$ & (mrad) & & & \\
\hline 120.75 & 35.125 & & 0 & 87 \\
\hline 122.25 & 35.561 & & 0 & 85 \\
\hline 123.75 & 35.997 & & 0 & 83 \\
\hline 125.25 & 36.434 & $:$ & 0 & 82 \\
\hline 126.75 & 36.870 & & 0 & 80 \\
\hline 128.25 & 37.306 & & 0 & 78 \\
\hline 129.75 & 37.743 & & 0 & 77 \\
\hline 131.25 & 38.179 & & 0 & 75 \\
\hline 132.75 & 38.615 & & 0 & 74 \\
\hline 134.25 & 39.052 & & 0 & 72 \\
\hline 135.75 & 39.488 & & 0 & 71 \\
\hline 137.25 & 39.924 & & 0 & 69 \\
\hline 138.75 & 40.361 & & 0 & 68 \\
\hline 140.25 & 40.797 & & 0 & 66 \\
\hline 141.75 & 41.233 & & 0 & 65 \\
\hline 143.25 & 41.670 & & 0 & 64 \\
\hline 144.75 & 42.106 & & 0 & 62 \\
\hline 146.25 & 42.542 & & 0 & 60 \\
\hline 147.75 & 42.979 & & 0 & 59 \\
\hline 149.25 & 43.415 & & 0 & 58 \\
\hline 150.75 & 43.851 & & 0 & 56 \\
\hline 152.25 & 44.288 & & 0 & 54 \\
\hline 153.75 & 44.724 & & 0 & 53 \\
\hline 155.25 & 45.160 & & 0 & 52 \\
\hline 156.75 & 45.597 & & 0 & 50 \\
\hline 158.25 & 46.033. & & 0 & 49 \\
\hline 159.75 & 46.469 & & 0 & 48 \\
\hline 161.25 & 46.906 & & 0 & 46 \\
\hline 162.75 & 47.342 & & 0 & 45 \\
\hline 164.25 & 47.778 & & 0 & 44 \\
\hline 165.75 & 48.215 & & 0 & 42 \\
\hline 167.25 & 48.651 & & 0 & 40 \\
\hline 168.75 & 49.087 & & 0 & 39 \\
\hline 170.25 & 49.524 & & 0 & 37 \\
\hline 171.75 & 49.960 & & 0 & 36 \\
\hline 173.25 & 50.396 & & 0 & 35 \\
\hline 174.75 & 50.833 & & 0 & 33 \\
\hline 176.25 & 51.269 & & 0 & 32 \\
\hline 177.75 & 51.705 & & 0 & 30 \\
\hline 179.25 & 52.142 & & 0 & 29 \\
\hline
\end{tabular}


Table 4-2. STAKDARD SOLAR SGAN FOR LINE FOCUS GBOMETRY (concluded)

\begin{tabular}{|c|c|c|c|}
\hline \multicolumn{2}{|c|}{$\theta$} & \multirow{2}{*}{$\begin{array}{l}\text { Solar } \\
\left(W / \mathrm{m}^{2}\right.\end{array}$} & \multirow{2}{*}{$\begin{array}{c}\text { Circumsolar Region } \\
\left(\mathrm{W} / \mathrm{m}^{2}\right. \\
\mathrm{rad})\end{array}$} \\
\hline$(m 1 n)$ & (mrad) & & \\
\hline $\begin{array}{l}180.75 \\
182.25 \\
183.75 \\
185.25 \\
186.75\end{array}$ & $\begin{array}{l}52.578 \\
53.014 \\
53.451 \\
53.877 \\
54.323\end{array}$ & $\begin{array}{l}0 \\
0 \\
0 \\
0 \\
0\end{array}$ & $\begin{array}{l}27 \\
26 \\
24 \\
23 \\
21\end{array}$ \\
\hline
\end{tabular}

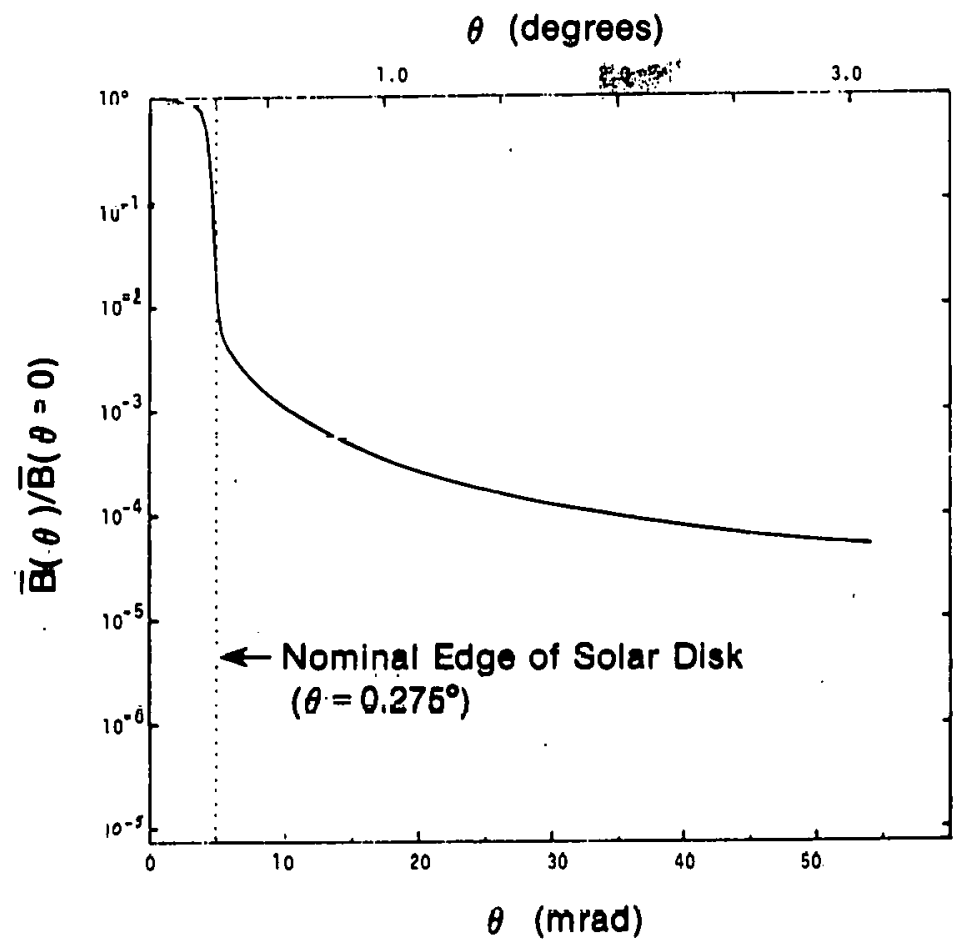

Figure 4-1. Brightness Dlstrlbution (In Relative Unlts) of Standard Clrcumsolar Scan 
Table 4-1 will predict the intercept factor $\gamma_{s}$ for the solar disk with an rms error of about 0.0002 . The solar disk portion of the distribution in Table 4-1, therefore, is recommended as the best avallable brightness distribution for the limb- darkened solar disk.

The validity of the linear model in Fig. 2-3 for the threshold dependence of the average circumsolar ratio $R_{a v}(q)$ is shown by Table 4-3, where $R_{a v}(q)$ for each of the files in the LBL data set is 1isted for various thresholds $q$. 
Table 4-3. MONTHLY AVERAGE CIRCUMSOLAR RATIO $\mathrm{R}_{\mathrm{av}}(q)$ VERSUS THRESHOLD q FOR EACH FILE

\begin{tabular}{|c|c|c|c|c|c|c|c|c|}
\hline \multirow[b]{2}{*}{ File } & \multirow[b]{2}{*}{ Location } & \multirow[b]{2}{*}{ Yr/Mo } & \multirow{2}{*}{$\begin{array}{l}\text { Hours } \\
\text { of Data }\end{array}$} & \multicolumn{5}{|c|}{$q\left(W / m^{2}\right)$} \\
\hline & & & & 0 & 50 & 150 & 300 & 500 \\
\hline 1 & Atlanta & $\begin{array}{l}77 / 06 \\
77 / 07 \\
77 / 08 \\
77 / 09 \\
77 / 10 \\
77 / 11 \\
77 / 12\end{array}$ & $\begin{array}{r}163 \\
251 \\
273 \\
123 \\
246 \\
103 \\
73\end{array}$ & $\begin{array}{l}0.081 \\
0.063 \\
0.109 \\
0.076 \\
0.036 \\
0.039 \\
0.049\end{array}$ & $\begin{array}{l}0.078 \\
0.059 \\
0.100 \\
0.071 \\
0.034 \\
0.033 \\
0.044\end{array}$ & $\begin{array}{l}0.070 \\
0.051 \\
0.083 \\
0.058 \\
0.031 \\
0.029 \\
0.034\end{array}$ & $\begin{array}{l}0.057 \\
0.041 \\
0.060 \\
0.043 \\
0.027 \\
0.020 \\
0.022\end{array}$ & $\begin{array}{l}0.039 \\
0.026 \\
0.039 \\
0.024 \\
0.019 \\
0.013 \\
0.018\end{array}$ \\
\hline 2 & Atlanta & $\begin{array}{l}78 / 01 \\
78 / 02 \\
78 / 03 \\
78 / 04 \\
78 / 05 \\
78 / 06\end{array}$ & $\begin{array}{l}191 \\
234 \\
228 \\
135 \\
173 \\
216\end{array}$ & $\begin{array}{l}0.057 \\
0.055 \\
0.043 \\
0.068 \\
0.050 \\
0.071\end{array}$ & $\begin{array}{l}0.051 \\
0.049 \\
0.040 \\
0.064 \\
0.045 \\
0.066\end{array}$ & $\begin{array}{l}0.045 \\
0.044 \\
0.037 \\
0.056 \\
0.033 \\
0.061\end{array}$ & $\begin{array}{l}0.034 \\
0.033 \\
0.030 \\
0.050 \\
0.023 \\
0.050\end{array}$ & $\begin{array}{l}0.022 \\
0.023 \\
0.025 \\
0.039 \\
0.018 \\
0.031\end{array}$ \\
\hline 3 & A1 bq. & $\begin{array}{l}76 / 05 \\
76 / 06 \\
76 / 07 \\
76 / 08 \\
76 / 09 \\
76 / 10 \\
76 / 11 \\
76 / 12\end{array}$ & $\begin{array}{r}80 \\
318 \\
199 \\
326 \\
106 \\
297 \\
260 \\
254\end{array}$ & $\begin{array}{l}0.021 \\
0.029 \\
0.027 \\
0.032 \\
0.040 \\
0.040 \\
0.024 \\
0.036\end{array}$ & $\begin{array}{l}0.020 \\
0.028 \\
0.026 \\
0.031 \\
0.039 \\
0.039 \\
0.024 \\
0.035\end{array}$ & $\begin{array}{l}0.019 \\
0.025 \\
0.024 \\
0.028 \\
0.037 \\
0.035 \\
0.023 \\
0.033\end{array}$ & $\begin{array}{l}0.016 \\
0.022 \\
0.017 \\
0.025 \\
0.027 \\
0.030 \\
0.022 \\
0.029\end{array}$ & $\begin{array}{l}0.015 \\
0.018 \\
0.014 \\
0.020 \\
0.019 \\
0.021 \\
0.017 \\
0.024\end{array}$ \\
\hline 4 & $\mathrm{~A} 1 \mathrm{bq}$. & $\begin{array}{l}77 / 01 \\
77 / 02 \\
77 / 03 \\
77 / 04 \\
77 / 05\end{array}$ & $\begin{array}{r}254 \\
242 \\
59 \\
301 \\
282\end{array}$ & $\begin{array}{l}0.040 \\
0.046 \\
0.060 \\
0.039 \\
0.036\end{array}$ & $\begin{array}{l}0.037 \\
0.045 \\
0.058 \\
0.037 \\
0.035\end{array}$ & $\begin{array}{l}0.031 \\
0.040 \\
0.051 \\
0.033 \\
0.031\end{array}$ & $\begin{array}{l}0.023 \\
0.036 \\
0.039 \\
0.028 \\
0.026\end{array}$ & $\begin{array}{l}0.017 \\
0.028 \\
0.027 \\
0.022 \\
0.022\end{array}$ \\
\hline 5 & $\mathrm{Albq}$. & $\begin{array}{l}77 / 06 \\
77 / 07 \\
77 / 09 \\
77 / 10 \\
77 / 11 \\
77 / 12\end{array}$ & $\begin{array}{l}159 \\
303 \\
234 \\
239 \\
221 \\
202\end{array}$ & $\begin{array}{l}0.054 \\
0.041 \\
0.039 \\
0.041 \\
0.058 \\
0.053\end{array}$ & $\begin{array}{l}0.053 \\
0.040 \\
0.039 \\
0.040 \\
0.057 \\
0.052\end{array}$ & $\begin{array}{l}0.050 \\
0.036 \\
0.036 \\
0.039 \\
0.054 \\
0.049\end{array}$ & $\begin{array}{l}0.042 \\
0.031 \\
0.031 \\
0.037 \\
0.048 \\
0.042\end{array}$ & $\begin{array}{l}0.031 \\
0.024 \\
0.027 \\
0.032 \\
0.034 \\
0.036\end{array}$ \\
\hline 6 & Ft. Hood & $\begin{array}{l}76 / 07 \\
76 / 08 \\
76 / 09 \\
76 / 10 \\
76 / 11 \\
76 / 11 \\
76 / 12\end{array}$ & $\begin{array}{r}131 \\
361 \\
121 \\
115 \\
88 \\
84 \\
155\end{array}$ & $\begin{array}{l}0.040 \\
0.034 \\
0.041 \\
0.050 \\
0.027 \\
0.035 \\
0.053\end{array}$ & $\begin{array}{l}0.039 \\
0.033 \\
0.040 \\
0.049 \\
0.026 \\
0.032 \\
0.051\end{array}$ & $\begin{array}{l}0.037 \\
0.031 \\
0.036 \\
0.047 \\
0.025 \\
0.026 \\
0.044\end{array}$ & $\begin{array}{l}0.035 \\
0.026 \\
0.036 \\
0.041 \\
0.024 \\
0.021 \\
0.036\end{array}$ & $\begin{array}{l}0.027 \\
0.022 \\
0.029 \\
0.033 \\
0.011 \\
0.016 \\
0.027\end{array}$ \\
\hline
\end{tabular}


Table 4-3. MONTHLY AVERAGE CIRCOHSOLAR RATIO $R_{a v}(q)$ VERSUS THRESHOLD q FOR EACH FILE (concluded)

\begin{tabular}{|c|c|c|c|c|c|c|c|c|}
\hline \multirow[b]{2}{*}{ File } & \multirow[b]{2}{*}{ Location } & \multirow[b]{2}{*}{ Yr/Mo } & \multirow{2}{*}{$\begin{array}{l}\text { Hours } \\
\text { of Data }\end{array}$} & \multicolumn{5}{|c|}{$q\left(W / m^{2}\right)$} \\
\hline & & & & 0 & 50 & 150 & 300 & 500 \\
\hline \multirow[t]{4}{*}{7} & Ft. Hood & $77 / 01$ & 155 & 0.062 & 0.061 & 0.058 & 0.047 & 0.037 \\
\hline & & $77 / 02$ & 165 & 0.053 & 0.052 & 0.049 & 0.042 & 0.031 \\
\hline & & $77 / 03$ & 248 & 0.084 & 0.081 & 0.075 & 0.063 & 0.049 \\
\hline & & $77 / 04$ & 101 & 0.027 & 0.027 & 0.026 & 0.024 & 0.021 \\
\hline \multirow[t]{5}{*}{8} & Ft. Hood & $77 / 07$ & 74 & 0.040 & 0.038 & 0.037 & 0.036 & 0.031 \\
\hline & Argonne & $77 / 08$ & 63 & 0.124 & 0.120 & 0.098 & 0.078 & 0.063 \\
\hline & & $77 / 09$ & 140 & 0.095 & 0.091 & 0.085 & 0.076 & 0.055 \\
\hline & & 71710 & 152 & 0.079 & 0.069 & 0.062 & 0.055 & 0.046 \\
\hline & & $77 / 12$ & $\begin{array}{l}130 \\
115\end{array}$ & $\begin{array}{l}0.094 \\
0.148\end{array}$ & $\begin{array}{l}0.083 \\
0.127\end{array}$ & $\begin{array}{l}0.0 / 3 \\
0.112\end{array}$ & 0.001 & $\begin{array}{l}0.043 \\
0.078\end{array}$ \\
\hline \multirow[t]{6}{*}{9} & China Lake & $76 / 07$ & 187 & 0.031 & 0.030 & 0.027 & 0.025 & 0.017 \\
\hline & & $76 / 08$ & 392 & 0.013 & 0.013 & 0.012 & 0.011 & 0.009 \\
\hline & & $76 / 09$ & 35 & 0.030 & 0.030 & 0.026 & 0.022 & 0.020 \\
\hline & & $76 / 10$ & 262 & 0.023 & 0.023 & 0.021 & 0.019 & 0.016 \\
\hline & & $76 / 11$ & 246 & 0.025 & 0.024 & 0.023 & 0.020 & 0.016 \\
\hline & & $76 / 12$ & 268 & 0.026 & 0.026 & 0.025 & 0.023 & 0.016 \\
\hline \multirow[t]{3}{*}{10} & China Lake & $77 / 01$ & 176 & 0.044 & 0.043 & 0.038 & 0.036 & 0.025 \\
\hline & & $77 / 02$ & 248 & 0.045 & 0.044 & 0.043 & 0.036 & 0.027 \\
\hline & & $77 / 03$ & 143 & 0.052 & 0.052 & 0.051 & 0.043 & 0.037 \\
\hline \multirow[t]{6}{*}{11} & Barstow & $77 / 07$ & 33 & 0.083 & 0.082 & 0.080 & 0.077 & 0.064 \\
\hline & & $77 / 08$ & 341 & 0.030 & 0.029 & 0.027 & 0.024 & 0.019 \\
\hline & & $77 / 09$ & 265 & 0.028 & 0.028 & 0.026 & 0.023 & 0.020 \\
\hline & & $77 / 10$ & 232 & 0.042 & 0.041 & 0.040 & 0.034 & 0.027 \\
\hline & & $77 / 11$ & 268 & 0.061 & 0.0 .59 & 0.0 .56 & 0.047 & 0.033 \\
\hline & & $77 / 12$ & 236 & 0.058 & 0.054 & 0.050 & 0.039 & 0.025 \\
\hline \multirow[t]{6}{*}{12} & Barstow & $78 / 01$ & 59 & 0.080. & 0.074 & 0.064 & 0.060 & 0.039 \\
\hline & & $78 / 02$ & 65 & 0.061 & 0.058 & 0.054 & 0.041 & 0.029 \\
\hline & & $78 / 03$ & 136 & 0.030 & 0.028 & 0.025 & 0.017 & 0.014 \\
\hline & & $78 / 04$ & 284 & 0.042 & 0.040 & 0.039 & 0.033 & 0.022 \\
\hline & & $78 / 05$ & 411 & 0.034 & 0.034 & 0.032 & 0.07 .8 & 0.025 \\
\hline & & $78 / 06$ & 247 & 0.024 & 0.024 & 0.023 & 0.022 & 0.020 \\
\hline
\end{tabular}




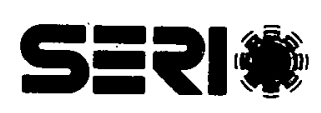


SECTION 5.0

\section{MEASURERIRITSS OF SOLAR RADLATION}

The LBL data map out the solar brightness up to an angle $\Delta=3.2^{\circ}$. This somewhat arbitrary cutoff was chosen in order to permit sufficlently accurate calculation of the radiation measured by a normal incidence pyrheliometer (NIP). To appreclate this detall one must recognize that the NIP does not have a sharp cutoff. at $2.75^{\circ}$ but $1 \mathrm{~s}$ characterized by the angular acceptance function in Fig. 5-1.* For angles below $3.2^{\circ}, f_{\text {NIP }}$ is given by

$$
\mathrm{f}_{\mathrm{NIP}}(\theta)= \begin{cases}1 & \text { for } \theta<0.02793 \mathrm{rad}\left(\text { or } 1.6^{\circ}\right) \\ 1.714-25.55 \theta & \text { for } 0.02793 \mathrm{rad}<\theta<0.05585 \mathrm{rad} .\end{cases}
$$

Because almost all avallable measurements of so-called direct or beam 1rradiance $I_{b}$ have been obtalned with a NIP and because this will also be the case in the foreseeable future, it is desirable to refer the intercept factor to $I_{b}$. On the other hand, we have followed the LBL group in defining the circumsolar component $I_{c}$ as the total irradiance between $0.275^{\circ}$ and $3.2^{\circ}$. This inclusion in $I_{c}$ of all radiation out to $3.2^{\circ}$ is motivated by the desire to calculate the insolation avallable to focusing collectors as accurately as the data permit (some focusing collectors do intercept some appreclable radiation that the pyrhellometer misses).

As a consequence of these definitions, $I_{b}$ is somewhat smaller than the 1rradiance $I_{s}+I_{c}$ on which all intercept factors calculated so far have been based. The difference between $I_{b}$ and $I_{s}+I_{c}$ is small on clear days but In- $^{-}$ creases with circumsolar ratio.

We want to reconcile the above definition of clrcumsolar radiation with the goal of providing a single expression for an intercept factor $\gamma$ that is based on $I_{b}$ so that $I_{1 n}$ can be obtalned from

$$
I_{\text {In }}=\gamma I_{b}
$$

The NIP behaves optically like a solar collector with angular acceptance function $f_{N I P}(\theta)$; hence, the Irradiance measured by a NIP is

$$
I_{b}=\gamma_{N I P}\left(I_{s}+I_{c}\right)
$$

*Information given by D. F. Grether in a telephone conversation. 


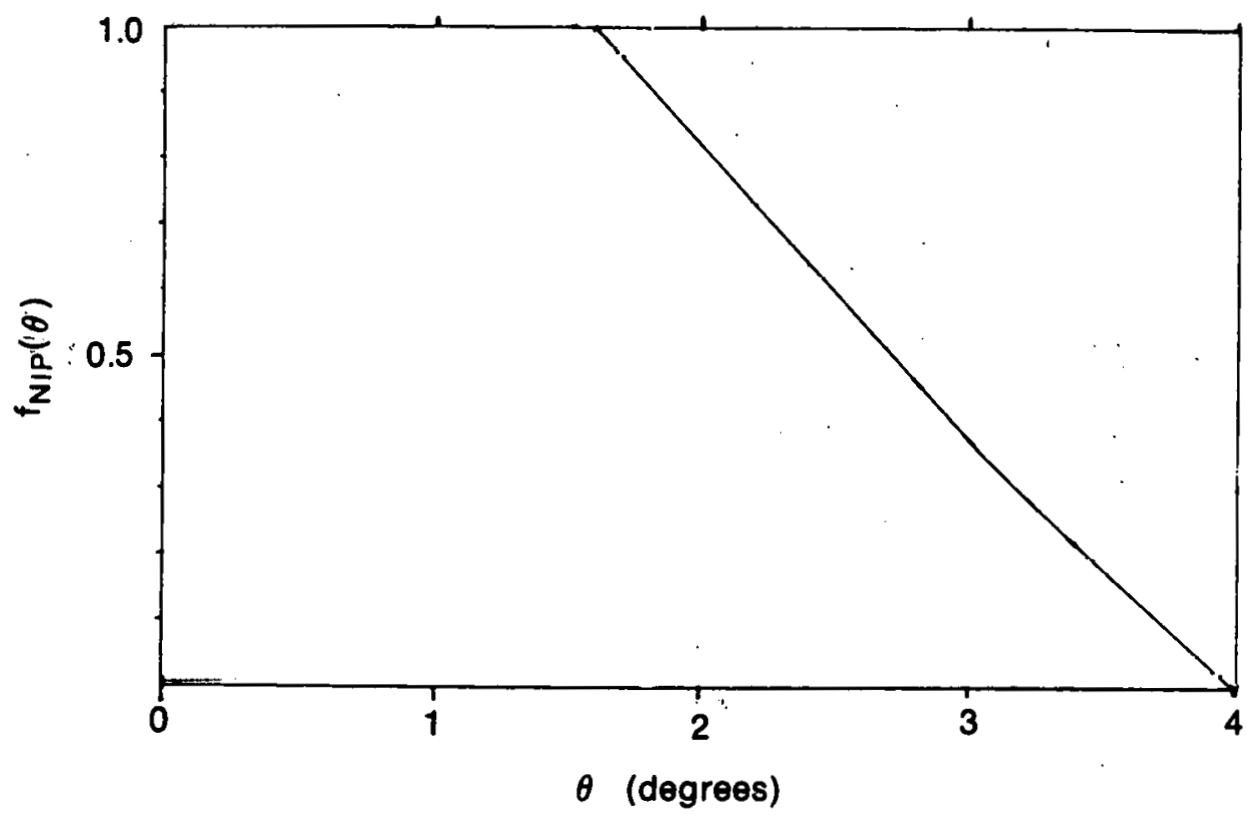

Figure 5-1. Angular Aoocptanoc Funotion of Pyrhellometer (NIP) 
where

$$
\gamma_{N I P}=\frac{2 \pi}{I_{s}+I_{c}} \int_{0}^{\Delta} \theta B(\theta) f_{N I P}(\theta) d \theta
$$

For the purpose of calculating long-term average intercept factors the standard scan (Table 4-1) can be used in Eq. 5-4 with the result

$$
\gamma_{\mathrm{NIP}, \mathrm{av}}=1-0.09632 \mathrm{R}_{\mathrm{av}}
$$

Now the intercept factor $\gamma_{s c \text {, av }}$ of Eq. 4-12, which was based on $\bar{I}_{s}+\bar{I}_{c}$, can be related to the beam irradiance $\overline{\mathrm{I}}_{\mathrm{b}}$. Equation 4-11 can be rewritten as

$$
\bar{I}_{\text {in }}=\gamma_{s c, a v}\left(\bar{I}_{s}+\bar{I}_{c}\right)
$$

Replacing $\overline{\mathrm{I}}_{s}+\overline{\mathrm{I}}_{\mathrm{c}}$ with $\overline{\mathrm{I}}_{\mathrm{b}} / \gamma_{\mathrm{NIP}, \mathrm{av}}$ from Eq. 5-3 yields

$$
\bar{I}_{\text {in }}=\frac{\gamma_{\text {sc,av }}}{\gamma_{\text {NIP, av }}} \bar{I}_{b} \text {. }
$$

Finaliy, Eqs. 4-12 and 5-5 are inserted to display the dependence ọ circumsolar ratio $\mathrm{R}_{\mathrm{av}}$

$$
\bar{I}_{\text {In }}=\frac{\gamma_{s, a v}-\left(\gamma_{s, a v}-\gamma_{c, a v}\right) R_{a v}}{1-0.09632 R_{a v}} \bar{I}_{b}
$$




\section{SEPI}




\section{SECTION 6.0}

\section{NURERICAL RESULTS AND VALIDATION}

To validate the linear model (Eq. 4-12), a wide range of parabolic dish collectors were considered, with concentration ratios $C=200,500,1000,2000$, 5000 , and 10,000 ; rim angles $\phi=30^{\circ}, 40^{\circ}, 50^{\circ}$, and $60^{\circ}$; optical errors ranging from $\sigma=1 \mathrm{mrad}$ to $30 \mathrm{mrad}$; and four operating thresholds $q=50,150$, 300 , and $500 \mathrm{~W} / \mathrm{m}^{2}$. The validation is typical of other focusing collectors as well, because any practical solar concentrator of concentration sufficiently high to be susceptible to circumsolar radiation has an angular acceptance function $f(\theta)$ with the same general behavior as a parabolic dish: $f(\theta)$ is constant out to an angle: $\theta$, and then decreases smoothly to zero at $\theta_{2}$. The above range of $C$ and $\phi$ values covers all typical cases.

For each collector design (i.e., for each value of $\phi, C$, and $\sigma$ ) and for each $\operatorname{scan} B_{i}(\theta)$ in the LBL data set,* the intercept factor $\gamma_{s c, i}$ was calculated exactly; i.e., according to Eq. 3-5. Then the exact long-term average intercept factor for each file was calculated as

$$
\gamma_{s c, \text { av ,exact }}=\frac{\sum_{+} \gamma_{s c, 1, \operatorname{exact}}\left(I_{s}+I_{c}\right)_{i}}{\sum_{i}\left(I_{s}+I_{c}\right)_{i}},
$$

the summation running over all scans in the file. With 120 collector designs, 4 threshold values, and 12 files, this required $4 \times 120 \times 12=5760$ hour-byhour simulations. Then $\gamma_{s c, a v}$, model for the linear model, Eq. 4-12, was calculated for each collector design and for each file of circumsolar data, and the error

$$
\varepsilon=\gamma_{\mathrm{sc}, \mathrm{av}, \text { model }}-\gamma_{\mathrm{sc}, \mathrm{av}, \text { exact }}
$$

was determined. To list $\varepsilon$ for each of the almost 6000 simulations may be more confusing than informative; hence, the results for several simulations were grouped together and the mean and the rms errors were calculated for each category.

Let $\varepsilon_{\mathrm{cqf}}$ designate the error (Eq. 6-2) for collector design c, threshold $q$, and file $f$. For each collector design $c$ (i.e., for each value of $c, \phi$, and $\sigma$ ), the mean error or bias was calculated as

*The original LBL data were measured in 10-minute intervals. The data supplied to us were hourly averages of the original measurements. 


$$
\bar{\epsilon}_{c}=\frac{1}{12} \sum_{\mathrm{f}=1}^{12} \frac{1}{4} \sum_{\mathrm{q}=1}^{4} \varepsilon_{\mathrm{cqf}}
$$

and the rms error as

$$
\bar{\varepsilon}_{\mathrm{c}, \mathrm{rms}}=\left(\frac{1}{12} \sum_{\mathrm{f}=1}^{12} \frac{1}{4} \sum_{\mathrm{q}=1}^{4} \varepsilon_{\mathrm{cqf}}^{2}\right)^{1 / 2} .
$$

The results are listed in Table 6-1, together with the values for $\gamma_{s, a v}$ and $\left(\gamma_{s, a v}-\gamma_{c, a v}\right)$ of the linear model for the long-term average intercept factor.

To evaluate possible location- or threshold-dependent trends, the mean and rms error for each file and threshold also have been calculated but averaged over all collector designs:

$$
\bar{\varepsilon}_{\mathrm{qf}}=\frac{1}{120} \sum_{\mathrm{c}=1}^{120} \varepsilon_{\mathrm{cqf}}
$$

and

$$
\bar{c}_{q f, r m s}=\left(\sum_{120}^{1} \sum_{c=1}^{120} c_{c q f}^{2}\right)^{1 / 2}
$$

These results, listed in Table 6-2, show that there is no significant pattern with regard to threshold or location.

The single most important measure of the error is provided by the average over all collector designs, thresholds, and files. The results for the bias error and for the rms error are

$$
\bar{\varepsilon}_{\text {total }}-\frac{1}{5760} \sum_{c=1}^{120} \sum_{q=1}^{4} \sum_{f=1}^{12} \varepsilon_{c q f}-0.00056
$$

and

$$
\bar{\varepsilon}_{\text {total, rms }}=\left(\frac{1}{5760} \sum_{c=1}^{120} \sum_{q=1}^{4} \sum_{f=1}^{12} \varepsilon_{c q f}\right)^{1 / 2}=0.0021 .
$$


Table 6-1. VALIDATION OF LINBAR MODET FOR INTERCBPT FACTOR FOR PARABOLIC DISH OF RIM ANGLIE $\phi$, CONCEITIRATION C, AND OPTICAI. ERROR ब

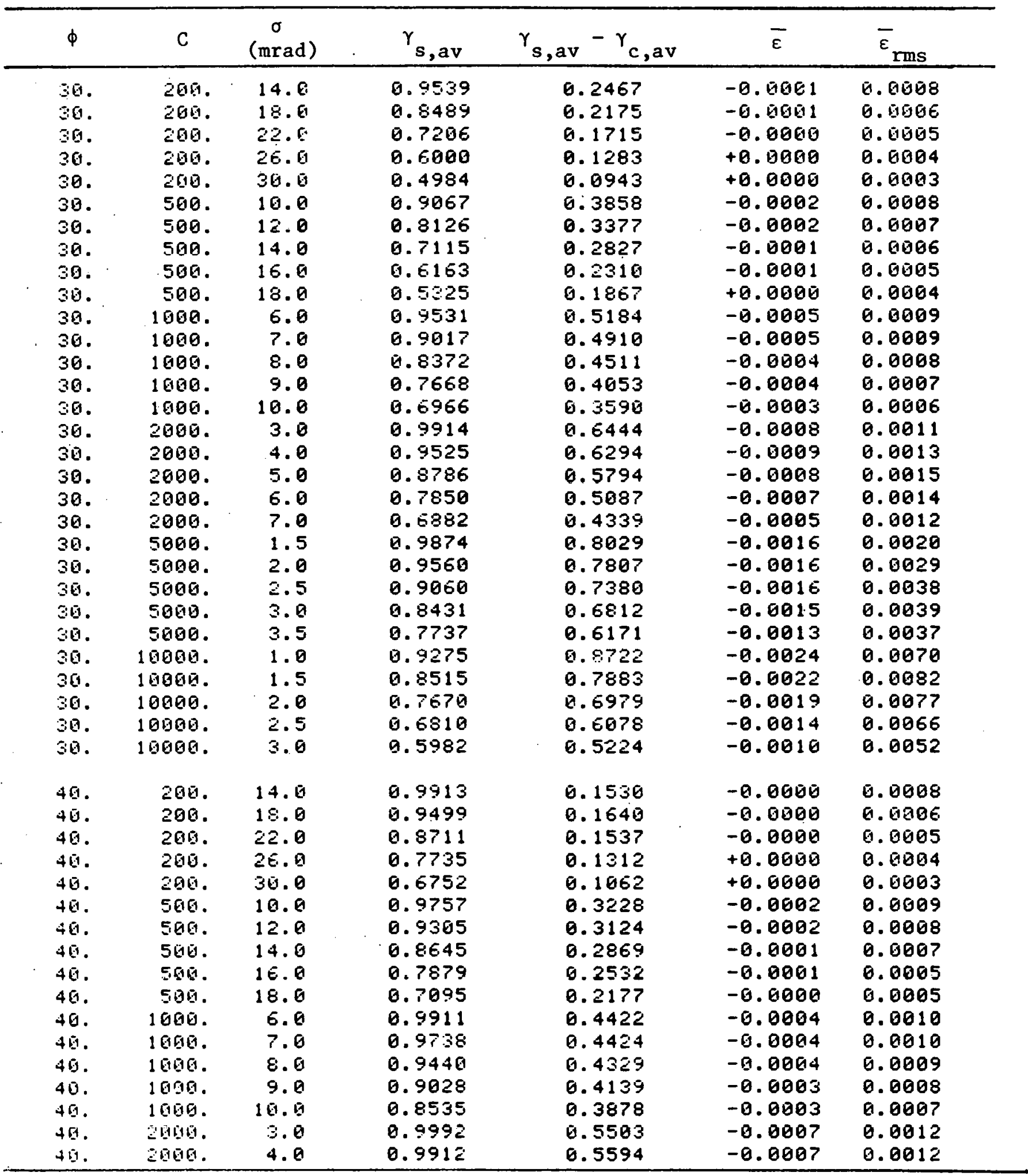


Table 6-1. VALIDATION OF LIMEAR MODEL FOR IMTERCEPT FACTOR FOR PARABOLIC DISH OF RIM ANGLE $\phi$, CONCENTRATION C, AND OPTICAL ERROR ब (continued)

\begin{tabular}{|c|c|c|c|c|c|c|}
\hline$\phi$ & C & $\begin{array}{c}\sigma \\
(\mathrm{mrad}) \\
\end{array}$ & $\gamma_{s, a v}$ & $\gamma_{s, a v}-\gamma_{c, a v}$ & $\bar{\varepsilon}$ & $\bar{\varepsilon}_{\mathrm{rms}}$ \\
\hline $\begin{array}{l}40 . \\
40 . \\
40 . \\
40 . \\
40 . \\
40 . \\
46 . \\
40 . \\
40 . \\
40 . \\
40 . \\
40 . \\
46 .\end{array}$ & $\begin{array}{c}2000 . \\
2000 . \\
2000 . \\
5000 . \\
5000 . \\
5000 . \\
5000 . \\
5000 . \\
10000 . \\
10000 . \\
10000 . \\
10090 . \\
10000 .\end{array}$ & $\begin{array}{l}5.0 \\
6.0 \\
7.0 \\
1.5 \\
2.0 \\
2.5 \\
3.0 \\
3.5 \\
1.0 \\
1.5 \\
2.0 \\
2.5 \\
3.0\end{array}$ & $\begin{array}{l}0.9644 \\
0.9145 \\
0.8472 \\
0.9991 \\
0.9934 \\
0.9779 \\
0.9497 \\
0.9094 \\
0.9909 \\
0.9627 \\
0.9132 \\
0.8487 \\
0.7762\end{array}$ & $\begin{array}{l}0.5540 \\
0.5277 \\
0.4847 \\
0.7108 \\
0.7152 \\
0.7108 \\
0.6938 \\
0.6641 \\
0.8395 \\
0.8185 \\
0.7740 \\
0.7131 \\
0.6437\end{array}$ & $\begin{array}{l}-0.0007 \\
-0.0006 \\
-0.0005 \\
-0.0013 \\
-0.0013 \\
-0.0014 \\
-0.0013 \\
-0.0012 \\
-0.0021 \\
-0.0020 \\
-0.0018 \\
-0.0015 \\
-0.0012\end{array}$ & $\begin{array}{l}0.0013 \\
0.0012 \\
0.0011 \\
0.0017 \\
0.0023 \\
0.0029 \\
0.0031 \\
0.0031 \\
0.0052 \\
0.0062 \\
0.0063 \\
0.0058 \\
0.0049\end{array}$ \\
\hline $\begin{array}{l}50 . \\
50 . \\
50 . \\
50 . \\
50 . \\
50 . \\
50 . \\
50 . \\
50 . \\
50 . \\
54 . \\
50 . \\
50 . \\
50 . \\
58 . \\
50 . \\
50 . \\
50 . \\
50 . \\
50 . \\
50 . \\
50 . \\
50 . \\
50 . \\
50 . \\
50 . \\
50 . \\
50 . \\
50 . \\
58 .\end{array}$ & 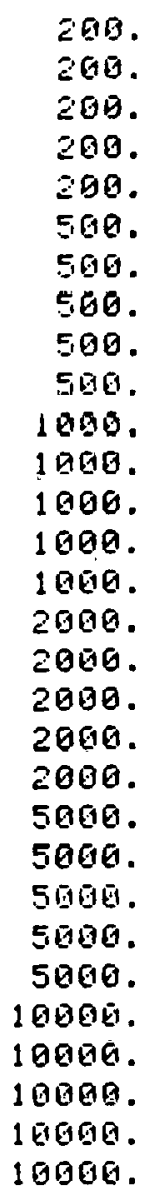 & $\begin{array}{l}14.0 \\
18.0 \\
22.0 \\
25.0 \\
30.0 \\
10.0 \\
12.0 \\
14.0 \\
16.0 \\
16.0 \\
6.0 \\
7.0 \\
8.0 \\
9.0 \\
10.0 \\
3.0 \\
4.0 \\
5.0 \\
6.0 \\
5.0 \\
1.5 \\
2.0 \\
3.5 \\
3.6 \\
3.5 \\
1.0 \\
1.5 \\
2.0 \\
2.5 \\
3.0\end{array}$ & $\begin{array}{l}9.9961 \\
0.9761 \\
0.9906 \\
0.9616 \\
0.7817 \\
0.9694 \\
0.9656 \\
9.9258 \\
9.9724 \\
0.8107 \\
9.9961 \\
9.9891 \\
0.9736 \\
0.9497 \\
0.9156 \\
0.9996 \\
0.9961 \\
0.9836 \\
0.9567 \\
0.9145 \\
0.9995 \\
0.9971 \\
0.9902 \\
0.9764 \\
0.9542 \\
0.9959 \\
0.9836 \\
0.9591 \\
0.9151 \\
0.9659\end{array}$ & $\begin{array}{l}5.9931 \\
0.1114 \\
0.1178 \\
0.1121 \\
0.0992 \\
0.2565 \\
0.2587 \\
0.2519 \\
0.2345 \\
0.2126 \\
0.378 \\
9.3823 \\
0.3925 \\
0.3765 \\
0.3547 \\
0.4885 \\
0.4973 \\
0.5009 \\
0.4935 \\
0.4731 \\
0.6477 \\
0.6526 \\
0.6548 \\
0.6512 \\
0.6399 \\
0.7762 \\
0.7719 \\
0.7551 \\
0.7233 \\
0.6786\end{array}$ & 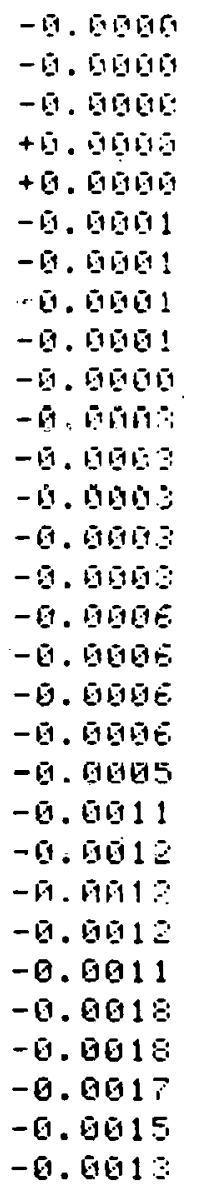 & 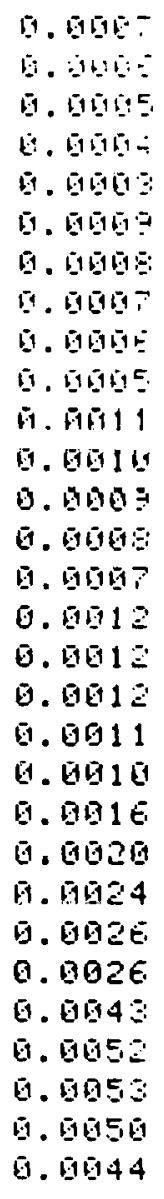 \\
\hline $\begin{array}{l}60 . \\
60 . \\
60 .\end{array}$ & $\begin{array}{l}200 . \\
200 . \\
200 .\end{array}$ & $\begin{array}{l}14.0 \\
18.6 \\
22.6\end{array}$ & $\begin{array}{l}0.9945 \\
9.9757 \\
1.9394\end{array}$ & $\begin{array}{l}0.0732 \\
0.0859 \\
0.0921\end{array}$ & $\begin{array}{l}-0.0000 \\
-0.0000 \\
+0.0008\end{array}$ & 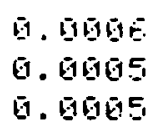 \\
\hline
\end{tabular}


Table 6-1. VALIDATIOA OF LIIBAR MODEL POR INTBRCBPT FACTOR FOR PARABOLIC DISH OF RIM ANGLR $\phi$, CONCBIIRATION C, AND OPTTCAL ERBOR - (concluded)

\begin{tabular}{|c|c|c|c|c|c|c|}
\hline$\phi$ & C & $\begin{array}{c}\sigma \\
\text { (mrad) }\end{array}$ & $\gamma_{\mathbf{s}, \mathrm{av}}$ & $\gamma_{\mathrm{g}, \mathrm{av}}-\gamma_{\mathrm{c}, \mathrm{av}}$ & $\bar{\varepsilon}$ & $\bar{\varepsilon}_{\mathrm{rms}}$ \\
\hline $\begin{array}{l}60 . \\
60 . \\
60 . \\
60 . \\
60 . \\
60 . \\
60 . \\
60 . \\
60 . \\
60 . \\
60 . \\
60 . \\
60 . \\
60 . \\
60 . \\
60 . \\
60 . \\
60 . \\
60 . \\
60 . \\
60 . \\
60 . \\
60 . \\
60 . \\
60 . \\
60 . \\
60 .\end{array}$ & $\begin{array}{l}200 . \\
200 . \\
500 . \\
500 . \\
500 . \\
500 . \\
500 . \\
1000 . \\
1000 . \\
1000 . \\
1000 . \\
1000 . \\
2000 . \\
2000 . \\
2000 . \\
2000 . \\
2000 . \\
5000 . \\
5000 . \\
5000 . \\
5000 . \\
5000 . \\
10000 . \\
10000 . \\
10000 . \\
10000 . \\
10000 .\end{array}$ & $\begin{array}{l}26.0 \\
30.0 \\
10.0 \\
12.0 \\
14.0 \\
16.0 \\
18.0 \\
6.0 \\
7.0 \\
8.0 \\
9.0 \\
10.0 \\
3.0 \\
4.0 \\
5.0 \\
6.0 \\
7.0 \\
1.5 \\
2.0 \\
2.5 \\
3.0 \\
3.5 \\
1.0 \\
1.5 \\
2.0 \\
2.5 \\
3.0\end{array}$ & $\begin{array}{l}0.8869 \\
0.8234 \\
0.9871 \\
0.9671 \\
0.9361 \\
0.8952 \\
0.8469 \\
0.9944 \\
0.9863 \\
0.9731 \\
0.9545 \\
0.9306 \\
0.9991 \\
0.9944 \\
0.9821 \\
0.9599 \\
0.9275 \\
0.9988 \\
0.9952 \\
0.9878 \\
0.9755 \\
0.9577 \\
0.9925 \\
0.9802 \\
0.9597 \\
0.9298 \\
0.8905\end{array}$ & $\begin{array}{l}0.0913 \\
0.0850 \\
0.2132 \\
0.2154 \\
0.2119 \\
0.2030 \\
0.1896 \\
0.3386 \\
0.3409 \\
0.3402 \\
0.3360 \\
0.3283 \\
0.4544 \\
0.4599 \\
0.4608 \\
0.4547 \\
0.4407 \\
0.6130 \\
0.6153 \\
0.6151 \\
0.6111 \\
0.6025 \\
0.7355 \\
0.7291 \\
0.7159 \\
0.6940 \\
0.6629\end{array}$ & $\begin{array}{l}+0.0000 \\
+0.0000 \\
-0.0001 \\
-0.0001 \\
-0.0001 \\
-0.0001 \\
-0.0000 \\
-0.0003 \\
-0.0003 \\
-0.0003 \\
-0.0003 \\
-0.0002 \\
-0.0005 \\
-0.0005 \\
-0.0005 \\
-0.0005 \\
-0.0005 \\
-0.0010 \\
-0.0010 \\
-0.0011 \\
-0.0011 \\
-0.0010 \\
-0.0017 \\
-0.0017 \\
-0.0016 \\
-0.0014 \\
-0.0013\end{array}$ & $\begin{array}{l}0.0004 \\
0.0003 \\
0.0005 \\
0.0005 \\
0.0007 \\
0.0006 \\
0.0005 \\
0.0011 \\
0.0010 \\
0.0009 \\
0.0009 \\
0.0005 \\
0.0012 \\
0.0012 \\
0.0012 \\
0.0011 \\
0.0016 \\
0.0015 \\
0.0018 \\
0.0022 \\
0.0023 \\
0.0023 \\
0.0038 \\
0.0046 \\
0.0047 \\
0.0045 \\
0.0040\end{array}$ \\
\hline
\end{tabular}


Table 6-2. BIAS $\bar{\varepsilon}$ AND rms ERROR $\bar{\varepsilon}$ AVERAGED OVER COLLECTOR DESIGNS, FOR DIFFERENT LOCATIONS HITH THRESHOLD q AND CIRCUHSOLAR

RATIO $\mathbf{R}_{\text {av }}$ -

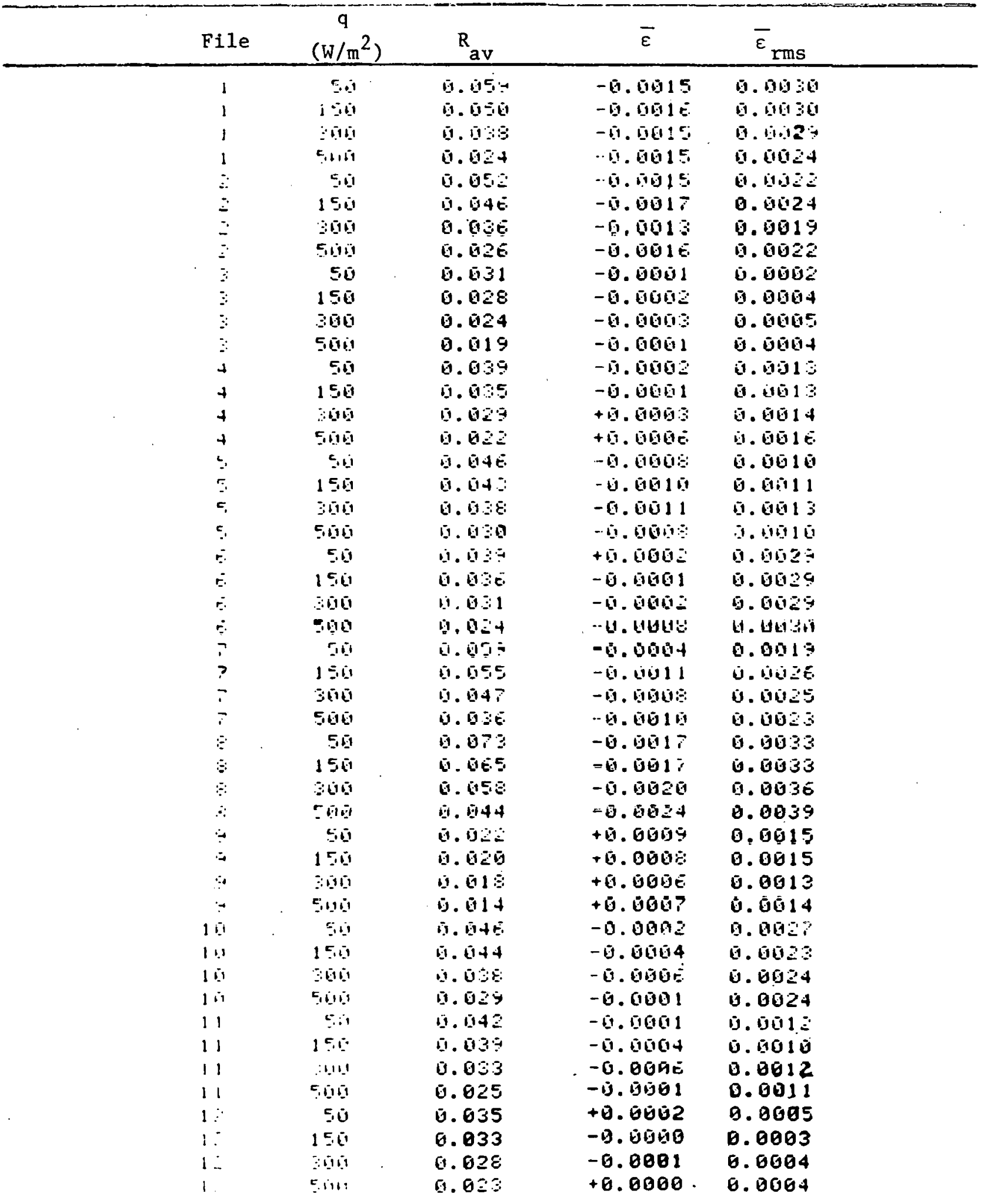


To put the results for the average errors into perspective, note that the circumsolar ratio varies considerably from year to year. For example, for the same month and for the same location (June, Albuquerque, N. Mex.), $R_{\text {av }}$ for $\mathrm{q}=50 \mathrm{~W} / \mathrm{m}^{2}$ is 0.028 in 1976 and 0.053 in 1977 ; as shown by Table 4-3. Since the coefficient $\left(\gamma_{s, a v}-\gamma_{c, a v}\right)$ of the circumsolar correction term for the average intercept factor is on the order of 0.5 , the inherent error of the linear model is much smaller than the error introduced by uncertainties in the circumsolar ratio (unless the averäge circumsolar ratio is known to better than 0.004 absolute error, which is unlikely to be the case in the near future). Furthermore, an error of a fraction of a percent in an intercept factor is very small compared to the uncertainty in the long-term average values of reflectance and absorptance. Therefore, the linear mode1 for the average intercept factor is satisfactory unless circumsolar ratios and material properties are known within a small fraction of a percent.

An interesting result from Table 6-1 concerns the rim angle dependence of the intercept factor. For a given $C$ and $\sigma$, the coefficients $\gamma_{s}$ av and $\gamma_{c, a v}$ can vary considerably with rim angle; e.g., for $C=500$ and $\sigma=10 \mathrm{mrad}$, the coefficient $\left(\gamma_{s, a v}-\gamma_{c, a v}\right)$ is 0.386 for $\phi=30^{\circ}$ and 0.213 for $\phi=60^{\circ}$. This implies that the collector with a $30^{\circ}$ rim angle is nearly twice as sensitive to circumsolar radiation as the collector with a $60^{\circ}$ rim angle. Therefore, an optical model with sharp angular cutoff, as assumed by Biggs and Vittitoe (1979) and Grether et al. (1977d), may not be sufficiently accurate for calculating the effect of circumsolar radiation.

For other concentrator types, e.g., Fresnel lenses and central receivers, the intercept factors $\gamma_{S}$, av and $\gamma_{c}$,av can be calculated in a simflar manner. Specific results for the important case of a parabolic trough with $90^{\circ}$ rim angle and cylindrical receiver are shown in Table 6-3 for a range of concentration $C$ and optical error $\sigma$, at normal incidence. It is instructive to compare these results with the ones for point focus parabolas. Whereas for point focus parabolas (Table 6-1) the value of $\left(\gamma_{s}, a v-\gamma_{c}, a v\right)$ ranges from 0.1 to 0.8 , values for the line focus parabolas are much smaller, in the range of 0.03 to 0.4 . Since the sensitivity to circumsolar radiation is proportional to $\left(\gamma_{s, a v}-\gamma_{c, a v}\right)$, the line focus parabolas tend to be significantly less sensitive to circumsolar radiation than point focus parabolas. [At nonnormal incidence the effect of circumsolar radiation on line focus collectors may be enhanced, however, because of an increase in the projected width of the sun (Bendt et a1. 1979).] This difference is easy to understand in terms of the rms angular width of the sun which is a factor $\sqrt{2}$ larger for point focus geometry than for line focus geometry. 
Table 6-3. THE IMIERCBPT FACTORS $\gamma_{\text {, a }}$ and $\left(\gamma_{g_{a}}-\dot{\gamma}_{c_{\text {av }}}\right)$ FOR PARABOLIC

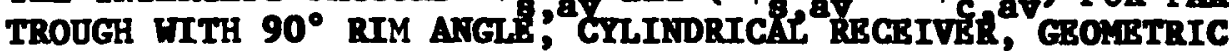
CORCBRTRATIOA C, AND TOTAL OPTICAL ERROR -

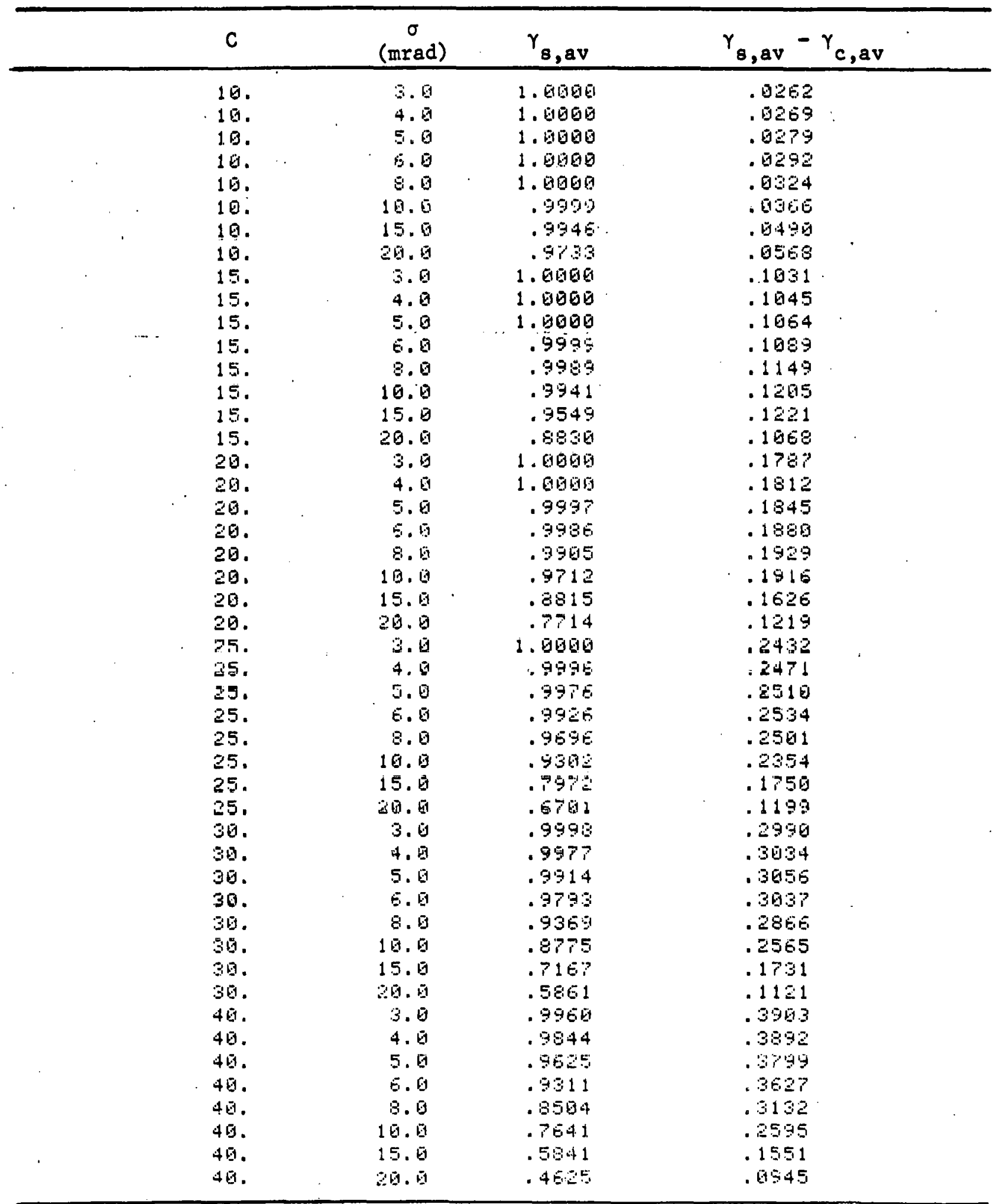




\section{SECTION 7.0}

\section{SURPAARY AND CONCLUSIONS}

Starting with a review of the circumsolar results provided by Lawrence Berkeley Laboratory (LBL) and with a description of the optical analysis of focusing collectors, we derived a simple prescription for incorporating circumsolar effects Into any analysis of solar energy systems. Both the effect on instantaneous performance (of interest for collector testing and for detalled system simulations) and the effect on long-term average performance (expressed as a correction term for calculations that did not take circumsolar radiation into account) have been treated. The formulas presented are at least as accurate as any circumsolar data that will be avallable in the foreseeable future. The results also suggest priorities for further acquisition and analysis of circumsolar data.

\subsection{INSTANTARTBOUS PERFORHANCE}

If the greatest possible accuracy in a system simulation is desired and if circumsolar data of the LBL type are avallable, Eq. 3-5 should be used for computing the collector performance for each circumsolar scan. For this purpose one first calculates the smeared angular acceptance function $f_{\sigma}(\theta)$. for the concentrator in question. The function $f_{\sigma}(\theta)$ depends only on the optics but not on insolation; its calculation is described in Section 3.0. Then $f_{\sigma}(\theta) \theta \Delta \theta$ is stored in memory at the beginning of the simulation; this involves 56 numbers, one for each of the angles at which the brightness has been measured by LBL ( $\Delta \theta$ is the increment between these angles). The intercepted irradiance $\mathrm{I}_{\mathrm{In}}$ for each scan is then computed according to the discrete version of Eq. 3-5:*

$$
I_{1 n}=2 \pi \sum_{1=1}^{56} B\left(\theta_{1}\right) f_{\sigma}\left(\theta_{1}\right) \theta_{i} \Delta \theta_{i},
$$

with $B\left(\theta_{1}\right)$ as the brightness of the scan at angle $\theta_{1}$. Equation $7-1$ requires 56 multiplications and additions, certainly not an excessive computational effort.

As for collector testing, the first step is to decide whether circumsolar radiation can have any detectable effect at all. For this purpose one calculates the coefficients $\gamma_{s, a v}$ and $\gamma_{c, a v}$ of the long-term average model (Eqs. 7-2

*Even though Eq. 7-1 has been derived for point focus geometry, it can also be used for line focus concentrations if the line focus angular acceptance function is transformed to the equivalent point focus angular acceptance function according to $\mathrm{Eq}$. 3-8. 
to 7-5). To ensure standardized test results, collectors should be tested only on very clear days. Since on clear days the circumsolar ratio ranges from less than 1 percent to, at most, a few percent, it follows that a collector test will be sensitive to circumsolar effects only if variations in the intercept factor on the order of $\Delta R\left(\gamma_{s, a v}-\gamma_{c, a v}\right)$ with $\Delta R \approx 0.01$ can be measured. If this is the case and if one wants to guarantee that the analysis is as accurate as possible, the brightness distribution of the sun should be monitored during the test with a circumsolar telescope of the LBL type. The intercepted radiation is then calculated according to Eq. 7-1. For example, Table 6-1 shows that parabolic dish collectors with a $45^{\circ} \mathrm{rim}$ angle and concentration below 1000 have $\left(\gamma_{s, a v}-\gamma_{c, a v}\right)$ values below 0.5 . If the experimental error in the optical efficiency

$$
\eta_{0}=(\rho \tau \alpha) \gamma
$$

is greater than $0.5 \Delta R \approx 0.005$, circumsolar radiation will have no detectable effect on tests of such collectors on clear days.

\subsection{LONG-TERM AVERAGR PERFORMANCE}

The simplest way to account for circumsolar effects on long-term average performance is to start with the usual pyrheliometer data for the heam irradiance $I_{b}$ and to calculate the intercepted irradiance

$$
I_{\text {in }}=\gamma_{a v} I_{b}
$$

with the intercept factor

$$
\gamma_{a v}=\frac{\gamma_{s, a v}-\left(\gamma_{s, a v}-\gamma_{c, a v}\right) R_{a v}(q)}{1-0.0963 R_{a v}(q)} .
$$

$\mathrm{R}_{\mathrm{av}}(\mathrm{q})$ is the long-term average circumsolar ratio (Eq. 4-13) for the location and period in question; to a good approximation it is a linear function of the threshold $q_{*}$ For the locations where circumsolar data are available, $R_{\text {ay }}(q)$ for $q=50 \mathrm{~W} / \mathrm{m}^{2}$ and $500 \mathrm{~W} / \mathrm{m}^{2}$ for each month has been calculated and listed in Table 4-3. The circumsolar ratio for any other threshold value $q$ can be found by linear interpolation.

The denominator of Eq. 7-3 corrects for the fact that a pyrheliometer does not measure all the circumsolar radiation out to angles of $3.2^{\circ}$ that has been included in the calculation of $\mathrm{R}_{\mathrm{av}}$ (see Section 5.0 for details).

* In thermal collectors the threshold is the heat loss divided by the optical efficiency. 
The coefficients $\gamma_{s, \text { av }}$ and $\gamma_{c}$, av needed in Eq. 7-3 are the intercept factors for radiation from the solar disk and from the circumsolar region, respective$1 y$, as calculated for the standard scan. This standard scan is the simple average over all circumsolar scans measured by LBL and it can be used for any location. It is listed in Tables 4-1 for point focus and in Table 4-2 for line focus geometry. For point focus collectors, the coefficients $\gamma_{s}$, av and $\gamma_{c, a v}$ are calculated from these scans according to the discrete versions of Eqs. 4-14 and 4-15,

$$
\gamma_{s, a v}=\sum_{i=1}^{11} w_{s}\left(\theta_{i}\right) \bar{B}\left(\theta_{i}\right) f_{\sigma}\left(\theta_{i}\right)
$$

and

$$
\gamma_{c, a v}=\sum_{i=12}^{56} w_{c}\left(\theta_{i}\right) \bar{B}\left(\theta_{i}\right) f_{\sigma}\left(\theta_{i}\right),
$$

where

$$
\begin{aligned}
\xi_{\sigma}= & \text { smeared angular acceptance function (convolution of angular ac- } \\
& \text { ceptance function } f \text { with Gaussian error distribution of width } \sigma) \\
& \text { (see Eq. } 3-4) ; \\
\bar{B}= & \text { brightness, from second column of Table } 4-1 ; \\
\mathrm{w}_{S}, w_{C}= & \text { weighting factors, for correct normalization, from third and } \\
& \text { fourth columns of Table 4-1; }
\end{aligned}
$$

these quantities are evaluated at angle $\theta_{i}$, first column of Table 4-1.

The values for $f_{\sigma}, \bar{B}$, and $w$ are determined for each of the 56 angles $\theta$ for which the LBL telescopes have provided data. For point focus geometry, the weighting factors have been calculated according to the formulas

$$
w_{s}\left(\theta_{i}\right)=\frac{\theta_{i} \Delta \theta_{i}}{\sum_{k=1}^{11} \bar{B}\left(\theta_{k}\right) \theta_{k} \Delta \theta_{k}}
$$

and

$$
w_{r}\left(\theta_{i}\right)=\frac{\theta_{i} \Delta \theta_{i}}{\sum_{k=12}^{56} \bar{B}\left(\theta_{k}\right) \theta_{k} \Delta \theta_{k}} .
$$


For line focus geometry the angle $\theta$ is omitted in the numerator and denominator, and hence the welghting factors for line focus collectors are constants, independent of $\theta_{1}$, if Table 4-2 with its equal angular increments is used for the standard circumsolar scan:

$$
w_{s, 1 \text { ine }}=\frac{1}{\sum_{i=1}^{11} \bar{B}_{1 \text { ine }}\left(\theta_{1}\right)}=\frac{1}{784,201 \mathrm{~W} / \mathrm{m}^{2} \mathrm{rad}}
$$

and

$$
w_{c, L i n e}=\frac{1}{\sum_{i=1}^{12 b} \bar{B}_{\text {line }}\left(\theta_{i}\right)}=\frac{1}{29,379 \mathrm{~W} / \mathrm{m}^{2} \mathrm{rad}} .
$$

Hence, the intercept factors for line focus geometry can be calculated most easily from the equations

$$
\gamma_{s, a v, 1 \text { ine }}=w_{s, 1 \text { ine }} \sum_{i=1}^{11} \cdot \bar{B}_{\text {line }}\left(\theta_{1}\right) f_{\sigma}\left(\theta_{i}\right)
$$

and

$$
\gamma_{c, a v, 1 \text { ine }}=w_{c, 11 n e} \sum_{i=1}^{125} \bar{B}_{11 n e}\left(\theta_{1}\right) f_{\sigma}\left(\theta_{1}\right) .
$$

An example illustrates the use of this formalism. Table 6-1 1ists some typical parabolic dishes with their relevant optical parameters. For each collector, $\gamma_{s, a v}$ and $\left(\gamma_{s, a v}-\gamma_{c, a v}\right)$ have been calculated according to Eqs. 7-4 and 7-5. A parabolic dish with concentration $C=1000$, rim angle $\phi=40^{\circ}$, and total optical error with rms width $\sigma=7 \mathrm{mrad}$ has the coefficients

$$
\gamma_{s, a v}=0.9738
$$

and

$$
\gamma_{s, a v}-\gamma_{c, a v}=0.4424
$$

Suppose the operating threshold is $q=100 \mathrm{~W} / \mathrm{m}^{2}$; the corresponding average circumsolar ratio is found by linear interpolation between the $q=50 \mathrm{~W} / \mathrm{m}^{2}$ and the $q=150 \mathrm{~W} / \mathrm{m}^{2}$ entries in Table 4-3. One of the lowest ratios in the table occurred in Albuquerque, N. Mex., in May 1976 with $R_{a v}\left(50 \mathrm{~W} / \mathrm{m}^{2}\right)=0.020$ and $R_{a v}\left(150 \mathrm{~W} / \mathrm{m}^{2}\right)=0.019$; hence, $R_{a v}\left(100 \mathrm{~W} / \mathrm{m}^{2}\right)=0.0195$. The corresponding intercept factor is, from Eq. 7-3, 


$$
\gamma_{a v}=\frac{0.9738-(0.4424 \times 0.0195)}{1-(0.0963 \times 0.0195)}=0.967
$$

with respect to the radiation $I_{b}$ measured by a pyrhellometer. The highest average circumsolar ratio observed so far 18 that for Argonne, Ill., In August 1977. Interpolation ylelds $R_{a v}\left(100 \mathrm{~W} / \mathrm{m}^{2}\right)=0.120$, and the corresponding intercept factor 1s $\gamma_{a v}=0.931$, some $4 \%$ lower than that for Albuquerque In May 1976.

\subsection{AVERAGE SUN SHAPB AND LMGB DARKENTNG}

It is a we11-known fact that the brightness of the solar disk as viewed from the earth is not uniform. Several investigators have recommended formulas to describe this so-called 11mb darkening (e.g., Biggs and Vittitoe 1979). These formulas, however, were based on rather limited measurements, and thus it was not clear to what extent they were really relevant for solar energy calculations. Our investigation has shown that a simple unweighted average over all circumsolar scans, when truncated at the solar radius $\delta=0.275^{\circ}$, is an excellent representation of limb darkening. (This value is slightly larger than the actual radius because of the limited angular resolution of the LBT, data.) More precisely, when the intercept factor $\gamma_{s}$ of point focus solar collectors for radiation from the solar disk is calculated for each scan in the LBL set and compared with the value $\gamma_{s}$, av corresponding to the average sun shape, the rms error is at most 0.0002 . We recommend, therefore, the average sun shape in Table 4-1 as the best choice for solar energy calculations in applications without spectral selectivity.

Similarly the analysis has shown that the average effect of circumsolar radiation can be calculated by means of a single standard brightness distribution in the circumsolar region; $1 . e .$, at angles between $\delta=0.275^{\circ}$ and $\Delta=3.2^{\circ}$. This distribution is also obtained from the average overall circumsolar profiles. The deviation of individual circumsolar scans from this shape is quite large; however, the average Intercept factor $\gamma_{c}$, av can 3 till be calculated with an accuracy of \pm 0.002 .

As for the connection between solar and circumsolar shapes, the model introduces a discontinuity in the brightness distribution at the edge of the sun because the relative magnitudes of the solar and the circumsolar brightness profiles are allowed to vary with circumsolar ratio. This is not objectionable because it is carried out in a logically consistent manner. Also, at the edge of the sun the brightness of most scans drops very sharply by several orders of magnitude.

\subsection{SPECTRAL EFPBCTS}

Because only spectrally averaged data were available, the numerical results of our analysis are applicable only to collectors without significant variation 
of sensitivity within the solar spectrum. However, the formalism is independent of the spectrum, and the same analysis could and probably should be carried out for concentrators with photovoltaic receivers since the LBL telescope has also measured circumsolar data for separate portions of the solar spectrum.

\subsection{NEED FOR FURTHER DATA OR CORRELATIONS}

Circumsolar effects on focusing collectors are relatively small and, for practical applications, the effect on long-term average performance is of greatest interest. Therefore, a simple yet accurate correction procedure has been developed for predicting the average loss of performance due to circumolar radiation. The model needs only one number as input: the average rircumsolar ratio for the location and time period in question. As a single number, this average ratio (or quantities closely related to it) is much easier to measure and use than the detailed angular scans of the circumsolar telescope. For example, a modified pyrheliometer with variable field of view might be employed instead.

As an alternative to collecting actual data, one could attempt to correlate circumsolar ratios with beam irradiance and other quantities that might be relevant, such as air mass and diffuse irradiance. If reliable correlations of this type can be developed from the existing data base, then circumsolar effects at other locations can be predicted without additional data. 
SECTION 8.0

\section{REFERENCES}

Bendt, P.; Rabl, A. 1979. Optical Analysis of Point Focus Parabolic Radiation Concentrators. Golden, $\mathrm{CO}$ : Solar Energy Research Inst1tute; SERI/TR-34-336. Forthcoming.

Bendt, P.; Rabl, A.; Gaul, H. W.; Reed, K. A. 1979. Optical Analysis and Optimization of Line Focus Solar Collectors. Golden, CO: Solar Energy Research Institute; SERI/TR-34-092; September.

Biggs, F.; Vittitoe, C. N. 1979. The Helios Model for the Optical Behavior of Reflecting Solar Concentrators. Albuquerque, NM: Sandia Laboratories; SAND 76-0347.

Grether, D. F. 1979. Simplistic Maximum Scattering Model. Informal report. Grether, D. F.; Hunt, A. 1977. Description of the LBL Reduced Data Base. Informal report. 9 August.

Grether, D. F.; Hunt, A.; Wahlig, M. 1977a. Techniques for Measuring Circumsolar Radiation. Berkeley, CA: Lawrence Berkeley Laboratory; LBL-8345.

Grether, D. F.; Hunt, A.; Wahlig, M. 1977b. Circumsolar Radiation: Correlations with Solar Radiation. Berkeley, CA: Lawrence Berkeley Laboratory; 11 October.

Grether, D. F.; Hunt, A.; Wah11g, M. 1977c. Circumsolar Radiation: Sensitivity Analysis for Central Receiver Designs. Berkeley, CA: Lawrence Berkeley Laboratory; 23 October.

Grether, D. F.; Hunt, A.; Wahlig, M. 1977d. Circumsolar Radiation: Monthly Summarles of Effect on Focussing Solar Energy Collection Systems. Berkeley, CA: Lawrence Berkeley Laboratory; 31 October.

Grether, D. F.; Evans, D.; Hunt, A.; Wahlig, M. 1979. "Application of Circumsolar leasurements to Concentrating Collectors." International Solar Energy Society Congress. 28 May - 1 June; Atlanta, GA.

Rabl, A. 1976. "Comparison of Solar Concentrators." Solar Energy. Vol. 18: p. 93.

Winston, R. 1970. "Light Collection Within the Franework of Geometrical Optics." J. Optical Society of America. Vol. 60: p. 245. 


\section{SEPI畨}




\begin{tabular}{|c|c|c|}
\hline $\begin{array}{l}\text { Document Control } \\
\text { Page }\end{array}$ & \begin{tabular}{|c|l}
$\begin{array}{c}\text { 1. SERI Report No. } \\
\text { TR-34-093 }\end{array}$ & 2. NTIS Accession No. \\
\end{tabular} & 3. Recipient's Accession No. \\
\hline \multirow{2}{*}{\multicolumn{2}{|c|}{$\begin{array}{l}\text { 4. Title and Subtitle } \\
\text { Effect of Circumsolar Radiation on Performance } \\
\text { of Focusing Collectors }\end{array}$}} & $\begin{array}{l}\text { 5. Pudlication Date } \\
\text { April } 1980 \\
\end{array}$ \\
\hline & & 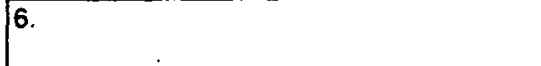 \\
\hline \multicolumn{2}{|l|}{ 7. Author(s) } & 8. Periorming Organization Rept. No. \\
\hline \multicolumn{2}{|c|}{ 9. Performing Organization Name and Address } & $\begin{array}{c}\text { 10. Project/Task/Work Unit No. } \\
3457.33\end{array}$ \\
\hline \multicolumn{2}{|c|}{$\begin{array}{l}\text { Solar Energy Research Institute } \\
1617 \text { Cole Boulevard } \\
\text { Golden, Colorado } 80401\end{array}$} & $\begin{array}{l}\text { 11. Contract (C) or Grant (G) No. } \\
\text { (C) } \\
\text { (G) }\end{array}$ \\
\hline \multirow{2}{*}{\multicolumn{2}{|c|}{ 12. Sponsoring Organization Name and Address. }} & $\begin{array}{l}\text { 13. Type of Report \& Period Covered } \\
\text { Technical Report }\end{array}$ \\
\hline & & 14. \\
\hline \multicolumn{3}{|l|}{ 15. Supplementary Notes } \\
\hline \multicolumn{3}{|c|}{$\begin{array}{l}\text { 16. Abstract (Limit: } 200 \text { words) Circumsolar radiation is one of several factors, along with } \\
\text { optical errors (contour, tracking, etc.), that determine the size and shape of the } \\
\text { solar image at the receiver of a concentrating collector. The sensitivity of a } \\
\text { collector to circumsolar radiation depends on insolation conditions and on col- } \\
\text { lector parameters; it increases with geometrical concentration ratio and decreases } \\
\text { with operating threshold. In this paper the Lawrence Berkeley Laboratory (LBL) } \\
\text { circumsolar data are used to develop fast computational procedures for calculating } \\
\text { the effect of circumsolar radiation on both the instantaneous and the long-term } \\
\text { average performance of focusing collectors. For predictions of long-term average } \\
\text { performance, a standard synthetic circumsolar scan has been developed that de- } \\
\text { scribes the brightness distribution of the solar disk ("limb darkening") and of } \\
\text { the circumsolar region. The radiation intercepted by a receiver is calculated } \\
\text { separately for the solar portion and for the circumsolar portion of this standard } \\
\text { sun shape, and these two contributions are then weighted according to the long- } \\
\text { term average circumsolar ratio for the location and period under study. } \\
\text {. }\end{array}$} \\
\hline \multicolumn{3}{|l|}{ 17. Document Analysis } \\
\hline \multicolumn{3}{|c|}{$\begin{array}{l}\text { a. Descriptors Circumsolar Radiation; Focusing Collectors; Insolation; Performance; } \\
\text { Pyrheliometers; Optical properties; Mathematical Models; Circumsolar } \\
\text { Scan }\end{array}$} \\
\hline \multicolumn{3}{|l|}{ c. UC Categgries } \\
\hline \multicolumn{3}{|l|}{62} \\
\hline \multirow{2}{*}{\multicolumn{2}{|c|}{$\begin{array}{l}\text { 18. Availability Statement } \\
\text { National Technical Information Service } \\
\text { U. S. Department of Commerce } \\
57.85 \text { Port Royal Road } \\
\text { Springfield, Virginia } 22161\end{array}$}} & $\begin{array}{r}\text { 19. No. of Pages } \\
65\end{array}$ \\
\hline & & $\begin{array}{rr}20 . \text { Price } & \\
& \$ 3.25\end{array}$ \\
\hline
\end{tabular}

